\title{
Artigos
}

\section{A reconfiguração da sociologia no Brasil: expansão institucional e mobilidade docente ${ }^{1}$}

Jacob Carlos Lima*

\section{Resumo}

Este artigo analisa a reconfiguração do campo da Sociologia no Brasil, tendo como recorte a expansão da graduação e da pós-graduação a partir dos anos 1980, que resultou num crescimento sem precedentes da pesquisa social no país. Esse processo se consolidou com a normatização da avaliação da pós-graduação, bem como com a implantação de políticas de fomento à formação e pesquisa e, a partir de 2003, de programas de expansão das universidades públicas, com novas universidades, novos campi, institutos federais e maior democratização do acesso a estudantes de baixa renda, cotistas e outros. Nesse período, houve uma forte renovação geracional propiciada, de um lado, pela abertura de novas vagas nas universidades públicas decorrentes de programas de expansão, como o PROUNI, e, de outro, pela aposentadoria de um número expressivo de professores que participaram da montagem e organização da pós-graduação de Sociologia em diferentes regiões do país. Esse conjunto de situações levou a um processo que estamos chamando de "nacionalização" do campo da Sociologia no Brasil. Nacionalização no sentido da construção de uma cultura acadêmica não mais restrita a pequenos grupos e regiões, mas à sua generalização pelo país de uma forma cada vez mais conectada com o desenvolvimento da disciplina internacionalmente. Para demonstrar essa afirmação utilizamos alguns indicadores: os dados do CCGE, que, por sua vez, utiliza dados da Plataforma Sucupira da Capes e da RAIS sobre número de cursos e titulados no mestrado e doutorado, assim como a situação diante do mercado de trabalho no período 1996-2014. Foram levantados também os cursos de graduação ativos no país a partir de 1933 e seu crescimento até 2018 através do site e-mec do Ministério da Educação. Utilizamos ainda a Plataforma Sucupira da Capes, para obter dados dos docentes disponíveis em todos os programas credenciados da área.

1 Uma versão preliminar deste texto foi apresentada no FÓRUM SBS /ANPOCS Internacionalização da Sociologia Brasileira: desafios e perspectivas, no $41^{\circ}$ Encontro Anual da ANPOCS em Caxambu (MG), outubro de 2018, mesa que se propunha a discutir algumas das questões aqui colocadas.

* Jacob Carlos Lima é professor titular no Departamento de Sociologia da Universidade Federal de São Carlos, é Doutor em Sociologia pela Universidade de São Paulo (1992), com Pós-doutorado no Department of Urban Studies and Development do Massachusetts Institute of Technology (EUA-2001). E-mail: calimajb@gmail.com. 


\section{Palavras-chave}

Sociologia no Brasil. Graduação e Pós-Graduação em Sociologia e Ciências Sociais. Institucionalização do campo da Sociologia.

\section{Abstract}

The article analyzes the reconfiguration of the sociology field in Brazil, from the expansion of undergraduate and graduate studies starting from the 1980s, which resulted in an unprecedented growth of social research in the country. This process was consolidated with the standardization of the graduate evaluation, as well as the implantation of development policies towards graduation and research. Moreover, since 2003, with the programs of public university expansion - new universities, new campuses, federal institutes of technical education - and the democratization of access to low-income students. During this period, there was a strong generational renewal promoted, on one hand, by the opening of new vacancies in public universities because of expansion programs, like PROUNI, and, on the other, the retirement of a significant number of professors and researches who participated in the organization of the graduate sociology studies in different areas of the country. This set of situations has led to a process we are calling the "nationalization" of the sociology field in Brazil. Nationalization in the sense of building an academic culture no longer restricted to small groups and areas, but to its generalization in the country in a more connected way with the development of the discipline internationally. In order to demonstrate this, we have used some indicators: the CCGE data, which, in turn, uses data from the Capes and RAIS Sucupira Platform, regarding the number of courses and master's and doctorate degrees, as well as the situation in the work market during the 1996-2014 period. The undergraduate courses active in the country, from 1933 and their growth until 2018, were obtained through the website of the Ministry of Education. We also used the Capes Sucupira Platform to obtain data regarding the faculty available and all accredited programs in the field.

\section{Keywords}

Sociology in Brazil. Under-Graduation and Graduation in Sociology and Social Sciences. Institutionalization of the Sociology Field.

Este texto objetiva discutir a reconfiguração do campo da Sociologia no Brasil, tendo como recorte a expansão da graduação e da pós-graduação a partir dos anos 1980, que resultou num crescimento sem precedentes da pesquisa social no país. Esse processo se consolidou com a normatização 
da avaliação da pós-graduação (que estabeleceu critérios de titulação e produção acadêmica), bem como com a implantação de políticas de fomento à formação e pesquisa e, a partir de 2003, de programas de expansão das universidades públicas, com novas universidades, novos campi, institutos federais e maior democratização do acesso a estudantes de baixa renda, cotistas e outros. Resultou dessa política o crescimento de cursos de graduação e pós-graduação e um mercado de trabalho com novas oportunidades de carreira aos titulados na área, num contexto de crescimento econômico e de implementação de políticas sociais.

Nesse período, houve uma forte renovação geracional propiciada, de um lado, pela abertura de novas vagas nas universidades públicas decorrentes de programas de expansão, como o PROUNI, e, de outro, pela aposentadoria de um número expressivo de professores que participaram da montagem e organização da pós-graduação de Sociologia em diferentes regiões do país. A nova geração destaca-se pela qualificação em centros nacionais e internacionais, refletindo-se numa maior atualização teóricometodológica, que propiciou uma maior padronização nos conteúdos ensinados, na formação de quadros e no estabelecimento de uma cultura acadêmica marcada pela publicação regular, na participação, seja em eventos acadêmicos nacionais e internacionais da disciplina, seja em redes nacionais e transnacionais de pesquisa. Essa renovação foi acompanhada pelo deslocamento geográfico dos doutores recém-concursados, rumo a departamentos e programas de pós-graduação localizados em diferentes regiões do país.

Esse conjunto de situações, e esta é nossa hipótese, levou a um processo que estamos chamando de "nacionalização" do campo da Sociologia no Brasil. Nacionalização no sentido da construção de uma cultura acadêmica não mais restrita a pequenos grupos e regiões, mas à sua generalização pelo país de uma forma cada vez mais conectada com o desenvolvimento da disciplina internacionalmente. A formação dos quadros da pós-graduação, ainda marcada pela presença dos programas pioneiros, diversifica-se cada vez mais através da abertura de cursos em todo o país com qualidade certificada por órgãos de regulação e fomento, como a Capes e o CNPq, baseando-se em critérios amplamente discutidos no campo, com seus consensos e conflitos. Embora ainda permaneça fortemente concentrada nos estados de São Paulo e Rio de Janeiro, a formação em Sociologia e Ciências Sociais está presente praticamente em todos os estados da federação, sendo que apenas a região Norte ainda não está plenamente atendida. 
A abertura de cursos de graduação e pós em novos campi, ou mesmo sua expansão nos demais, a partir de 2003, implicou deslocamentos espaciais numa dimensão ímpar, considerando os novos postos de trabalho abertos que canalizaram a demanda dos titulados sem vinculação institucional. Isto colocou novos desafios para se pensar a carreira de sociólogodocente-pesquisador em espaços sem tradição acadêmica ou de pesquisa, situação similar à existente, embora em menor escala, com a expansão das universidades federais havida na década de 1970. Essa expansão implicou a mobilidade espacial dos docentes e se verificou em dois momentos: na formação e na construção da carreira acadêmica. No primeiro caso, existe uma diversidade resultante da existência de cursos de pós-graduação nos locais de origem da formação graduada, o que mudou substancialmente nas últimas décadas. No segundo caso, vincula-se à inserção na carreira universitária em universidades públicas, privadas ou em atividades não acadêmicas. No caso da construção da carreira em uma universidade pública, a mobilidade fica mais evidente em seu início, tendendo depois à permanência em uma única universidade dada as especificidades da carreira. A partir daí essa mobilidade se manifesta mais na realização de pós-doutorados e na atuação como professores visitantes no país ou no exterior.

A pós-graduação, por sua vez, propiciou um diferencial na profissionalização do sociólogo, profissionalização aqui discutida nos limites da academia. Dados apresentados pela Capes apontam para uma situação positiva dos profissionais pós-graduados no mercado de trabalho no período de 2009 a 2014.

Neste quadro, procuramos apresentar alguns indicadores acerca dos cursos existentes e da composição do corpo docente dos programas de pósgraduação e sua diversificação. Os dados apontam essa mobilidade, mas não permitem verificar sua dimensão, uma vez que a pós-graduação filtra a entrada em favor de pesquisadores com maior produção ou engajamento na pesquisa, o que não é um impedimento em regiões com menor tradição acadêmica, mas represa nas demais. Além disso, a aposentadoria de um grande número de docentes que estiveram no início da institucionalização da pós-graduação não implicou necessariamente saída da pós-graduação, o que permite a transmissão de experiências e a manutenção de uma continuidade na formação e na pesquisa e uma certa complementação geracional. 
Entretanto, devemos lembrar que, durante a década de 1990, as universidades públicas enfrentaram grandes dificuldades em sua manutenção e expansão, em função de políticas de redução de gastos públicos e secundarização do ensino público enquanto política de governo. Com isso, a substituição de docentes ficou abaixo das necessidades, criando um gap geracional a partir dos concursos. Esse gap não aparece tanto a partir da participação docente na pós-graduação, exigindo um estudo mais extensivo acerca da composição dos departamentos de Sociologia e Ciências Sociais no país, o que não foi possível fazer para este texto.

Alguns indicadores dessa reconfiguração foram empregados nesta pesquisa: os dados do $\mathrm{CCGE}^{2}$, que, por sua vez, utiliza dados da Plataforma Sucupira da Capes e da RAIS sobre número de cursos e titulados no mestrado e doutorado, assim como a situação diante do mercado de trabalho no período 1996-2014. Foram levantados também os cursos de graduação ativos no país a partir de 1933 e seu crescimento até 2018 através do site e-mec do Ministério da Educação. Utilizamos ainda a Plataforma Sucupira da Capes, para obter dados dos docentes disponíveis em todos os programas credenciados da área. De forma complementar, selecionamos três departamentos de Sociologia e/ou Ciências Sociais com dados disponíveis on-line para complementação das informações acerca da mobilidade espacial docente.

Por fim, finalizamos com algumas observações sobre o campo da Sociologia e das Ciências Sociais no contexto das mudanças e lutas disciplinares na configuração da carreira.

\section{A graduação e a pós-graduação em Sociologia}

Podemos dizer que os tempos heroicos da disciplina, a partir dos cursos pioneiros de graduação e pós-graduação em Sociologia, foram encerrados com a reforma universitária de 1968, com a expansão do ensino superior privado e a instalação do novo formato da pós-graduação. O caráter ensaístico e as pesquisas que se tornaram canônicas na Sociologia brasileira nos seus primeiros 30 anos deram lugar então a uma cultura acadêmica marcada pela apresentação de resultados de pesquisa em seminários e

\footnotetext{
${ }^{2}$ CCGE (2016) - Centro de Gestão e Estudos Estratégicos. Mestres e doutores 2015 - Estudos da demografia da base técnico-científica brasileira.
} 
congressos nacionais e internacionais e sua publicação sistemática. A massificação do ensino superior veio acompanhada de um forte crescimento da comunidade acadêmica e de novos padrões de competição e cobrança de produção bem como de acesso a fontes de financiamento. Um processo sem volta que resultou ora em críticas ao produtivismo exacerbado dos órgãos de avaliação e fomento ora no reconhecimento de uma maior democratização no acesso da formação e mesmo da atuação profissional. O campo da Sociologia, antes restrito a pequenas comunidades de pesquisadores no Rio de Janeiro e São Paulo, deu lugar a uma vigorosa comunidade nacional de pesquisadores com crescente reconhecimento internacional pela qualidade da produção e formação ${ }^{3}$.

De 1933 a 1964, tivemos a abertura de 21 cursos de graduação em Sociologia e Política ou Ciências Sociais distribuídos em alguns estados da Federação. São Paulo concentrou a maioria com seis cursos, seguido pelo Rio de Janeiro com quatro, Rio Grande do Sul com três, Minas Gerais com dois, três no Nordeste (UFPE, UFBA, UFCG), um no Pará, um em Goiás e um no Paraná (Quadro 1). De certa forma, nesse período já podemos falar de uma formação distribuída nacionalmente, mas sem pesquisa de referência, que no geral se manteve de forma mais efetiva em São Paulo (ALMEIDA, 1987).

Quadro 1 - Cursos de graduação em Sociologia e/ou Ciências Sociais 1933-1964

\begin{tabular}{|c|c|c|c|}
\hline $\mathbf{N}^{\mathbf{0}}$ & Instituição & Município & $\begin{array}{c}\text { Ano de } \\
\text { fundação }\end{array}$ \\
\hline 01 & $\begin{array}{c}\text { Fundação Escola de Sociologia e } \\
\text { Política }\end{array}$ & São Paulo (SP) & 1933 \\
\hline 02 & USP & São Paulo (SP) & 1934 \\
\hline 03 & UFRJ (Universidade do Brasil) & Rio de Janeiro (RJ) & 1939 \\
\hline 04 & PUCRS & Porto Alegre (RS) & 1940 \\
\hline 05 & UFPR & Curitiba (PR) & 1940 \\
\hline
\end{tabular}

\footnotetext{
${ }^{3}$ Vários autores destacam esse período de formação com certa nostalgia de um passado idílico, no qual a universidade formava pessoas integrais, imbuídas da interdisciplinaridade do conhecimento. Pertinente enquanto uma crítica à burocratização e ao produtivismo do período posterior, não se considera, porém, o caráter extremamente restrito da universidade naquele período e mesmo da produção sociológica, limitada a um conjunto pequeno de textos canônicos. Sobre isso, vejam-se Leis (2000) e Perlatto (2017).
} 


\begin{tabular}{|c|c|c|c|}
\hline $\mathbf{N}^{\mathbf{0}}$ & Instituição & Município & $\begin{array}{c}\text { Ano de } \\
\text { fundação }\end{array}$ \\
\hline 06 & $\begin{array}{c}\text { UERJ (Universidade do Distrito } \\
\text { Federal) }\end{array}$ & Rio de Janeiro (RJ) & $1941(1953)^{4}$ \\
\hline 07 & UFMG & Belo Horizonte (MG) & 1941 \\
\hline 08 & UFBA & Salvador (BA) & 1941 \\
\hline 09 & PUCCAMP & Campinas (SP) & 1942 \\
\hline 10 & UFJF & Juiz de Fora (MG) & 1948 \\
\hline 11 & UFPE & Recife (PE) & 1950 \\
\hline 12 & UFPA & Belém (PA) & 1954 \\
\hline 13 & PUCRIO & Rio de Janeiro (RJ) & 1955 \\
\hline 14 & UNISINOS & São Leopoldo (RS) & 1958 \\
\hline 15 & UFRGS & Campina Grande & 1962 \\
\hline 16 & UFCG & (PB) & 1959 \\
\hline 17 & UFG & Goiânia (GO) & 1962 \\
\hline 18 & UNESP & Maráília (SP) & 1963 \\
\hline 19 & UNESP & São Paulo (SP) & 1964 \\
\hline 20 & PUCSP & Niterói (RJ) & 1964 \\
\hline 21 & UFF & & \\
\hline
\end{tabular}

Fonte: e-mec-MEC.

Nota: Não se consideram cursos abertos e fechados nesse período. O ano refere-se à autorização de funcionamento, o que nem sempre significou o início efetivo das atividades.

\footnotetext{
${ }^{4}$ Segundo Almeida (1987), a Universidade do Distrito Federal foi criada por iniciativa de Anísio Teixeira, então Secretário Municipal de Educação no governo de Pedro Ernesto em 1935, com quatro escolas: Escola de Filosofia e Letras; Instituto de Educação; Escola de Economia e Direito e Escola de Ciências. Buscava reproduzir o modelo da USP em São Paulo, com a proposta de uma universidade como "lugar de atividade científica livre e produção cultural desinteressada" (p.46). O contexto político da sua criação, entretanto, não foi favorável à sua continuidade. A partir da união de lideranças católicas conservadoras e o Ministério da Educação, o projeto foi abandonado e a reitoria entregue a Alceu de Amoroso Lima, que preparou o seu fechamento, que ocorreu em 1939. Em dezembro de 1950, foi criada a Universidade do Distrito Federal, atual UERJ, a partir de lei municipal. Embora com o mesmo nome, resultou da junção da Faculdade de Ciências Econômicas do Rio de Janeiro, da Faculdade de Direito do Rio de Janeiro, da Faculdade de Filosofia do Instituto La-Fayette e da Faculdade de Ciências Médicas. A Faculdade de Filosofia do Instituto La-Fayette, criada em 1939, em maio de 1941 teve a autorização de funcionamento do curso de Ciências Sociais, que iniciou suas atividades em 1953. (UERJ. A Universidade. Apresentação. Histórico) (emec-MEC).
} 
Na pós-graduação, tínhamos praticamente dois programas no sistema anterior de mestrados e doutorados tutoriais, ambos em São Paulo 5 . Esses programas não pressupunham disciplinas, mas poderiam exigir a presença em seminários, dependendo do professor orientador. No mais, as atividades exigidas eram a organização de estudos e a pesquisa individualizada devidamente orientada. A partir de 1965, com o Parecer CFE no 977/65, aprovado em dezembro daquele ano, o modelo de pósgraduação norte-americano, com mestrados e doutorados, disciplinas e áreas de concentração, foi regulamentado, embora já houvesse cursos nesse formato.

A Universidade São Paulo e a Escola de Sociologia e Política foram as pioneiras na área (Quadro 2), sendo que a primeira se adequou ao novo formato em 1971, e a Escola de Sociologia Política manteve a forma tutorial até 1986, quando encerrou seu mestrado e doutorado, no momento em que a Capes passou a regular a pós-graduação no país, autorizando o funcionamento dos cursos (BARREIRA; CORTES; LIMA, 2018).

\section{Quadro 2 - Cursos de Pós-graduação em Sociologia e/ou Ciências Sociais 1933-}

1971

\begin{tabular}{|c|c|c|c|c|c|}
\hline & Instituição & Cidade & $\begin{array}{l}\text { Ano de } \\
\text { início }\end{array}$ & $\begin{array}{c}\text { Produção } \\
\text { no formato } \\
\text { pré-reforma } \\
\text { de } 1971\end{array}$ & $\begin{array}{c}\text { Desdobramentos } \\
\text { posteriores }\end{array}$ \\
\hline 1 & $\begin{array}{l}\text { Fundação } \\
\text { Escola de } \\
\text { Sociologia e } \\
\text { Política de } \\
\text { São Paulo }\end{array}$ & $\begin{array}{c}\text { São } \\
\text { Paulo }\end{array}$ & $\begin{array}{c}\text { MS 1943- } \\
1986 \\
\text { DR } 1945- \\
1986\end{array}$ & $\begin{array}{c}244 \text { (até 1986) } \\
82 \text { (até 1986) }\end{array}$ & $\begin{array}{l}\text { O programa manteve } \\
\text { o formato anterior } \\
\text { à reforma e foi } \\
\text { desativado em } 1986 . \\
\text { Escola Pós-Graduada } \\
\text { mantém cursos lato } \\
\text { sensu em Ciências } \\
\text { Sociais (2016). }\end{array}$ \\
\hline
\end{tabular}

\footnotetext{
${ }^{5}$ Segundo Sucupira (1980: 3): “a ideia de cursos de doutorado surge, pela primeira vez, com a Reforma Francisco Campos, em 1931. O Estatuto das Universidades Brasileiras (Decreto n? 19.851, de 11 de abril de 1931) previa o doutoramento de tipo europeu, com defesa de tese, 'atendidas outras exigências regulamentares dos respectivos institutos'. Por sua vez, o Decreto n? 19.852, também de 11 de abril de 1931, que dispunha sobre a organização da Universidade do Rio de Janeiro, criava cursos regulares de doutorado no campo do direito e das ciências exatas e naturais. Tais cursos constituíam, de fato, uma pós-graduação, que hoje denominamos stricto sensu".
} 


\begin{tabular}{|c|c|c|c|c|c|}
\hline & Instituição & Cidade & $\begin{array}{l}\text { Ano de } \\
\text { início }\end{array}$ & $\begin{array}{l}\text { Produção } \\
\text { no formato } \\
\text { pré-reforma } \\
\text { de } 1971\end{array}$ & $\begin{array}{c}\text { Desdobramentos } \\
\text { posteriores }\end{array}$ \\
\hline 2 & $\begin{array}{l}\text { Universidade } \\
\text { de São Paulo }\end{array}$ & $\begin{array}{c}\text { São } \\
\text { Paulo }\end{array}$ & $\begin{array}{c}1934 \\
\text { (primeira } \\
\text { tese em } \\
\text { 1945; } 1^{\mathrm{a}} \\
\text { dissertação } \\
\text { defendida } \\
\text { em } 1953\end{array}$ & $\begin{array}{c}25 \\
\text { dissertações } \\
\text { (Até 1970) } \\
20 \text { teses (até } \\
\text { 1970) }\end{array}$ & $\begin{array}{c}\text { Adotou o novo } \\
\text { formato a partir de } \\
1971 .\end{array}$ \\
\hline
\end{tabular}

Fonte: Sociologia USP, 2017.

Dados fornecidos pela Escola de Sociologia e Política de São Paulo (2014).

A reforma educacional de 1968 decorreu da preocupação da ditadura militar com a autonomia técnica e científica do país, e a pós-graduação se tornou uma política para atingir esses objetivos, assim como também a expansão do ensino superior privado e estatal. A reforma pressupunha a organização e expansão do sistema de universidades federais e do sistema privado empresarial, a articulação das atividades de ensino e pesquisa praticamente inexistente, a abolição das cátedras vitalícias, a introdução do regime departamental e de carreira acadêmica, com o ingresso e a progressão docente vinculados à titulação acadêmica, e, por fim, a criação de uma política nacional de pós-graduação, através de planos nacionais de pós-graduação ${ }^{6}$.

No período pós-1965 até 1980, foram criados 15 mestrados ${ }^{7}$, embora nem sempre voltados apenas à Sociologia, como nos casos da UFBA, que era de Ciências Humanas, e da UFPE, que era integrado com Economia, situação similar ao de Campina Grande, e ainda o da ESALQ-USP, em Piracicaba, de Ciências Sociais Rurais com Economia e Sociologia, que não sobreviveu ${ }^{8}$ (Gráfico 1).

\footnotetext{
${ }^{6}$ Para uma análise da reforma educacional de 1968, veja-se Saviani (2008).

7 Sobre experiências anteriores de pós-graduação na área, veja-se Barreira, Cortês e Lima (2018).

${ }^{8}$ Foi criado na ESALQ-USP, em 1966, o Mestrado em Ciências Sociais Rurais com as áreas de concentração em Administração, Economia e Sociologia Rural. Em 1975, Economia Rural e Sociologia Rural constituíram mestrados separados. O mestrado em Sociologia Rural foi extinto em 1981 por conflitos políticos internos com o afastamento de professores.
} 
Gráfico 1 - Mestrados 1967-1980

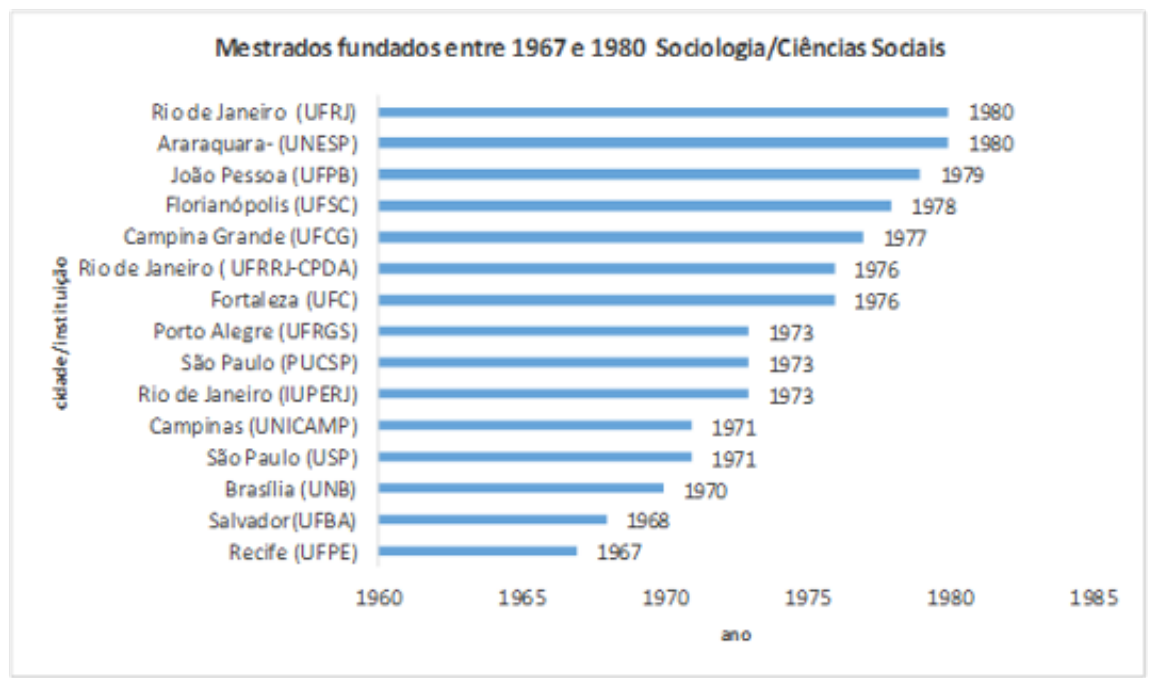

Fonte: Elaborado pelo autor a partir de dados da Capes (MEC-SESU, 2017).

Nota: A data de aprovação dos programas nem sempre coincide com seu funcionamento efetivo.

Os doutorados, com exceção da USP, tiveram início nos anos 1980, sendo que até 1990 seu número se restringia a cinco programas. Isso irá explicar que parte dos titulados, nesse período, obteve sua formação no exterior, vindo a compor o corpo docente da pós-graduação em expansão. Ilustrativo desse fato foi a composição dos credenciados do programa da UnB desde sua formação em 1970 até os anos $1990^{\circ}$ (Gráfico 2).

\footnotetext{
${ }^{9}$ Farias e Tavolaro (2017) destacam os docentes que compuseram os quadros do Departamento de Sociologia e da pós-graduação em vários momentos e da sua titulação doutoral.
} 


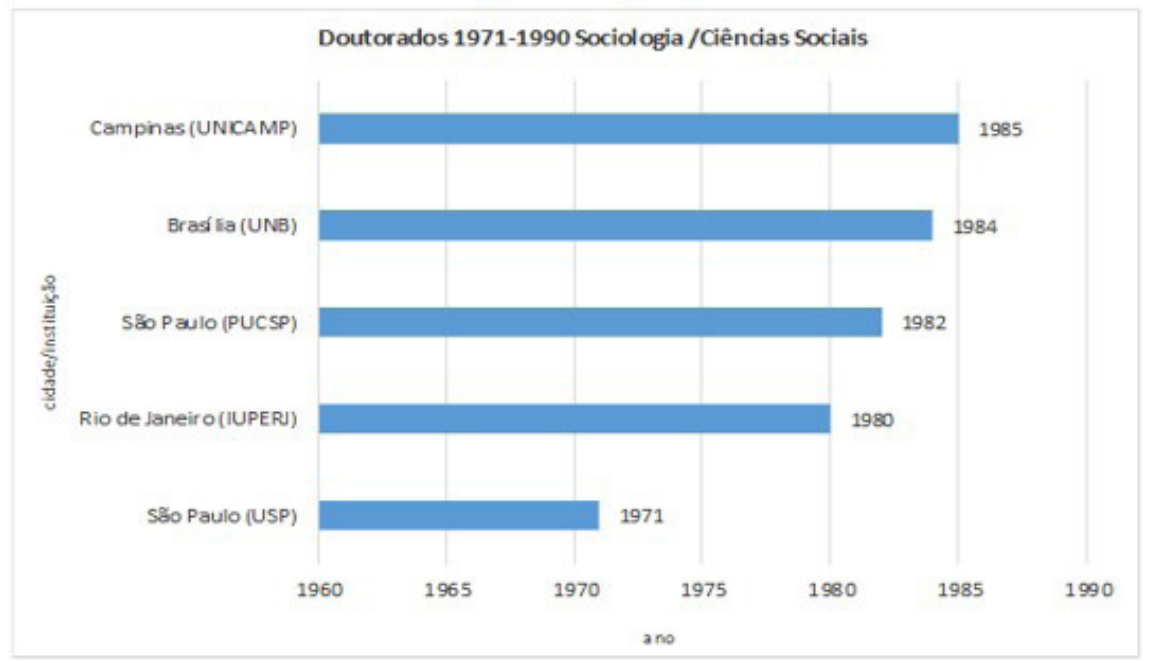

Fonte: Elaborado pelo autor a partir de dados da Capes (MEC-SESU, 2017).

A expansão das universidades federais e da pós-graduação provocou um primeiro deslocamento de docentes e pesquisadores para as diversas regiões do país, atraídos pelos novos postos de trabalho e um salário maior. Foi o caso, principalmente, das universidades do Norte e Nordeste, que receberam uma grande quantidade de docentes de todo o país e mesmo estrangeiros. Entre outros casos, podemos citar o da Universidade Federal do Acre, que, na década de 1970, por ser uma fundação, pagava salários mais altos que as universidades autárquicas, e outro, mais expressivo, da Universidade Federal da Paraíba, que, em função de um reitor que tinha sido presidente do CNPq e próximo aos militares, conseguiu investimentos que tornaram a Universidade o segundo maior orçamento entre as federais, atraindo docentes-pesquisadores nacionais e estrangeiros e investindo na expansão da graduação e pós-graduação. Nesse período foram criadas duas pós-graduações na Paraíba na área: o mestrado de Sociologia Rural em Campina Grande e o mestrado em Ciências Sociais em João Pessoa.

No âmbito da graduação, o período do regime militar promoveu a expansão de cursos privados em Ciências Sociais, mas que em sua maioria não sobreviveram. Alguns se mantiveram por mais de dez anos, mas a maioria fechou por não interessar às mantenedoras. Mesmo sendo cursos considerados "baratos", dada a baixa demanda, não são lucrativos (Quadro 3). 
Quadro 3 - Expansão da graduação em Ciências Sociais 1965-1985

\begin{tabular}{|c|c|c|c|c|c|}
\hline $\mathbf{N}^{\circ}$ & Instituição & Cidade & $\mathbf{1 9 6 0}$ & $\mathbf{1 9 7 0}$ & $\mathbf{1 9 8 0}$ \\
\hline 01 & Fundação Santo André & Santo André (SP) & 1966 & & \\
\hline 02 & UnB & Brasília (DF) & 1967 & & \\
\hline 03 & UERN & Mossoró (RN) & 1967 & & \\
\hline 04 & UFC & Fortaleza & 1968 & & \\
\hline 05 & Unimontes & Montes Claros (MG) & 1968 & & \\
\hline 06 & UFSC & Florianópolis (SC) & & 1972 & \\
\hline 07 & UEL & Londrina (PR) & & 1973 & \\
\hline 08 & UFRN & Natal (RN) & & 1974 & \\
\hline 09 & UFPI & Teresina (PI) & & & 1984 \\
\hline
\end{tabular}

Fonte: Elaborado pelo autor com dados do e-mec MEC, 2017.

Como esse dado inclui apenas os cursos ativos, apenas nove cursos novos foram registrados, que se somariam aos 21 existentes anteriormente (seis privados). Entretanto, dados do MEC, de 1973, computam a existência de 75 cursos, sendo que destes 49 estariam no Sudeste, o que permite ter uma ideia da dimensão da expansão do ensino privado após 1968 e de sua mortalidade (I PNPD 1975-1979). Em 1985, existiam apenas 30 cursos no país. Cerca de 45, aproximadamente, foram abertos a partir de 1965 e fechados posteriormente ${ }^{10}$. É interessante observar que a repressão política do período não impediu o aumento do número de cursos, embora tenha perseguido alunos e professores.

As crises econômicas e políticas nos estertores do regime militar inibiram novos investimentos nas universidades federais, provocando uma degradação da infraestrutura, greves generalizadas, comprometendo a permanência de docentes e impactando no desenvolvimento do ensino da graduação e pós-graduação ${ }^{11}$.

Mesmo assim, devemos destacar a implementação de políticas de capacitação docente pela CAPES e CNPq a partir do I PNPG - Plano Nacional de Pós-Graduação -1975-1979, para a titulação docente nos programas do Sudeste do país e do exterior, aumentando a mobilidade de

\footnotetext{
${ }^{10}$ Não conseguimos dados acerca do número de cursos abertos e desativados no período.

${ }^{11}$ A primeira universidade federal em São Paulo foi a UFSCar, no interior do Estado. Apenas a partir de 2003 outras universidades federais foram criadas em São Paulo, a Unifesp e a UFABC.
} 
docentes-pesquisadores. Além disso, tiveram início os encontros anuais da ANPOCS (1977), que marcaram o início dos congressos nacionais de forma sistemática, possibilitando maior visibilização da produção acadêmica do setor, até então muito restrita (BARREIRA; CORTÊS; LIMA, 2018). No início dos anos 1980, retornam do exterior os primeiros docentes titulados através do PICD, em grande parte vinculados a universidades do Norte-Nordeste, atraídos para o Sul-Sudeste e Distrito Federal por melhores condições de trabalho e acesso à pesquisa e à pós-graduação.

Na década de 1980, a pós-graduação em Sociologia teve um crescimento discreto com apenas quatro novos cursos de mestrado (UFMG, UFS, UFRN, UFSCar). Nos anos 1990 foram abertos 10 novos mestrados e 11 doutorados, mudando a configuração espacial da formação na área, apesar da falta de investimentos nas universidades federais.

\section{A expansão no período pós-2003}

A expansão do período 2003-2012 resulta de um conjunto de políticas públicas tendo no REUNI a sua versão mais completa. O programa, criado em 2007, integrava o Plano Nacional de Educação e resultou na criação de 18 novas universidades federais e 173 campi em cidades do interior do país. Resultou na mobilização e deslocamentos de docentes, em sua maioria titulados como doutores, para todas as regiões do país, criando novas demandas de pesquisa e financiamentos. Nos institutos federais, o crescimento foi maior ainda: das 140 escolas existentes no país em 2002, foram construídas mais 500 unidades, que passaram a integrar 644 campi. Em grande parte deles, a disciplina Sociologia está presente e, em alguns casos, com cursos de graduação em Ciências Sociais.

$\mathrm{Na}$ graduação temos agora uma nova situação decorrente dessa expansão. São 120 cursos, sendo 109 presenciais e majoritariamente em universidades públicas, com licenciaturas e bacharelados em todas as regiões do país (Tabela 1). 
Tabela 1 - Cursos de graduação em Sociologia e Ciências Sociais 1933-2017

\begin{tabular}{|c|c|c|c|c|c|c|}
\hline Tipo de instituição & $\begin{array}{c}\mathbf{1 9 3 3 -} \\
\mathbf{1 9 6 4}\end{array}$ & $\begin{array}{c}\mathbf{1 9 6 5 -} \\
\mathbf{1 9 8 5}\end{array}$ & $\begin{array}{c}\mathbf{1 9 8 6} \\
\mathbf{2 0 0 2}\end{array}$ & $\begin{array}{c}\mathbf{2 0 0 3 -} \\
\mathbf{2 0 1 7}\end{array}$ & EaD & Total \\
\hline Públicas & 16 & 08 & 20 & 49 & 01 & $\begin{array}{c}94 \\
(78,3 \%)\end{array}$ \\
\hline $\begin{array}{c}\text { Confessionais/sem } \\
\text { fins lucrativos }\end{array}$ & 05 & 01 & - & 01 & - & $07(5,8 \%)$ \\
\hline Privadas & - & - & 02 & 07 & 10 & $\begin{array}{c}19 \\
(15,8 \%)\end{array}$ \\
\hline Total & 21 & $\begin{array}{c}09 \\
(42,8 \%)\end{array}$ & $\begin{array}{c}22 \\
(71 \%)\end{array}$ & $\begin{array}{c}57 \\
(109,6 \%)\end{array}$ & 11 & $\begin{array}{c}120 \\
(100 \%)\end{array}$ \\
\hline
\end{tabular}

Fonte: e-mec-MEC; IES.

Nota: Apenas cursos ativos em setembro de 2017. O cálculo considera a licenciatura e o bacharelado na mesma instituição como um único curso. Algumas universidades ou escolas privadas têm autorização para o funcionamento do curso ativo, mas não significa que estejam funcionando. Para minimizar a diferença ente os autorizados e os em funcionamento, entramos no site de cada instituição privada.

Na pós-graduação, na avaliação quadrienal de 2013-2016, 53 programas foram avaliados, sendo que destes 31 com mestrados e doutorados, um apenas com doutorado, 19 mestrados acadêmicos e dois mestrados profissionais (sendo que dois mestrados e dois doutorados foram descredenciados). Depois da avaliação, até 2018, foram aprovados mais quatro doutorados (UFPel, UFSM, UFF, UFRRJ) e um mestrado (UFMAImperatriz).

$\mathrm{O}$ crescimento da área comparativamente às áreas de Antropologia e Ciência Política, que compõem no país as Ciências Sociais stricto sensu, ilustra o crescimento da área dentro da pós-graduação brasileira. Entre 1996-2014, houve um crescimento de $145 \%$ no número de mestrados e 166,7\% no de doutorados (Tabela 2). 
Tabela 2 - Número e percentagem de programas de mestrado em 2014 e taxa de crescimento entre 1996 e 2014, por áreas do conhecimento

\begin{tabular}{|c|c|c|c|c|}
\hline \multirow{2}{*}{$\begin{array}{c}\text { Classificação } \\
\text { áreas na } \\
\text { Capes }\end{array}$} & \multirow{2}{*}{$\begin{array}{c}\text { Área do } \\
\text { conhecimento }\end{array}$} & $\begin{array}{c}|c| \\
\text { Número } \\
\mathbf{( 2 0 1 4 )}\end{array}$ & $\mathbf{\%}(\mathbf{2 0 1 4})$ & $\begin{array}{c}\text { Crescimento } \\
\text { (\%) 1996-2014 }\end{array}$ \\
\hline 80 & Total & 3.620 & 100,00 & 204,97 \\
\hline 29 & Sociologia & 49 & 1,35 & 145 \\
\hline 38 & $\begin{array}{c}\text { Ciência } \\
\text { Política }\end{array}$ & 37 & 1,02 & 270 \\
\hline 53 & Antropologia & 23 & 0,64 & 130 \\
\hline
\end{tabular}

Fonte: CGEE - Mestres e doutores 2015 - Estudos da demografia da base técnicocientífica brasileira (Organização Social supervisionada pelo Ministério da Ciência, Tecnologia, Inovações e Comunicações (MCTIC) - dados Coleta Capes/ Plataforma Sucupira e RAIS.

A área de Ciência Política foi a que mais cresceu (270\%), seguida pela Sociologia (145\%) e pela Antropologia (130\%), acompanhando uma tendência de autonomização das chamadas Ciências Sociais stricto sensu e a profissionalização de seus quadros (Tabela 3).

Tabela 3 - Número e percentagem de programas de doutorado em 2014 e taxa de crescimento entre 1996 e 2014, por áreas do conhecimento

\begin{tabular}{|c|c|c|c|c|}
\hline \multirow{2}{*}{$\begin{array}{c}\text { Classificação } \\
\text { áreas na } \\
\text { Capes }\end{array}$} & $\begin{array}{c}\text { Área do } \\
\text { conhecimento }\end{array}$ & $\begin{array}{c}\text { Número } \\
\mathbf{( 2 0 1 4 )}\end{array}$ & $\mathbf{\%}(\mathbf{2 0 1 4})$ & $\begin{array}{c}\text { Crescimento } \\
\text { (\%) 1996-2014 }\end{array}$ \\
\hline 80 & Total & 1954 & 100,0 & 210,2 \\
\hline 19 & Sociologia & 32 & 1,64 & 166,7 \\
\hline 44 & $\begin{array}{c}\text { Ciência } \\
\text { Política }\end{array}$ & 17 & 0,87 & 466,7 \\
\hline 51 & Antropologia & 15 & 0,77 & 200,0 \\
\hline
\end{tabular}

Fonte: CGEE - Mestres e doutores 2015 - Estudos da demografia da base técnicocientífica brasileira (Organização Social supervisionada pelo Ministério da Ciência, Tecnologia, Inovações e Comunicações (MCTIC)- dados Coleta Capes/ Plataforma Sucupira e RAIS).

Esse percentual do crescimento no mestrado refletiu-se no aumento da titulação na Sociologia (145\%), ficando atrás da Ciência Política (466,7\%) e da Antropologia (200\%), conforme Tabela 4. 
Tabela 4 - Número e percentagem de títulos de mestrado concedidos no Brasil no ano de 2014 e taxa de crescimento entre 1996 e 2014, por áreas do conhecimento

\begin{tabular}{|c|c|c|c|c|}
\hline \multirow{2}{*}{$\begin{array}{c}\text { Classificação } \\
\text { Áreas na } \\
\text { Capes }\end{array}$} & \multirow{2}{*}{$\begin{array}{c}\text { Área do } \\
\text { conhecimento }\end{array}$} & $\begin{array}{c}|c| \\
\text { Número } \\
\mathbf{( 2 0 1 4 )}\end{array}$ & \% (2014) & $\begin{array}{c}\text { Crescimento } \\
\text { (\%) 1996-2014 }\end{array}$ \\
\hline 80 & Total & 50.206 & 100,00 & 378,97 \\
\hline 26 & Sociologia & 646 & 1,29 & 145 \\
\hline 46 & $\begin{array}{c}\text { Ciência } \\
\text { Política }\end{array}$ & 351 & 0,70 & 303,45 \\
\hline 54 & Antropologia & 255 & 0,51 & 193,10 \\
\hline
\end{tabular}

Fonte: CGEE - Mestres e doutores 2015 - Estudos da demografia da base técnicocientífica brasileira (Organização Social supervisionada pelo Ministério da Ciência, Tecnologia, Inovações e Comunicações (MCTIC) - dados Coleta Capes/ Plataforma Sucupira e RAIS).

Os dados da Sociologia refletem a consolidação da área e uma preocupação de manter o crescimento em níveis sustentáveis, num momento em que a pós-graduação está disseminada por todo o país, com exceção dos estados do Acre, Rondônia, Amapá e Roraima.

A realização do mestrado e doutorado, consecutivamente, aponta uma preocupação com a formação para a carreira acadêmica num momento de expansão das possibilidades de emprego, de mudanças na carreira docente das universidades públicas, nas quais o título de doutor passou a ser condição de ingresso, com políticas governamentais de incentivo à pós-graduação com financiamentos para os programas e bolsas para parte significativa dos alunos. Nesse período, a trajetória de formação nos três níveis representou cerca de $34 \%$ dos titulados e que, em certa medida, foram absorvidos pela expansão do mercado acadêmico e não acadêmico no país, seja nas universidades públicas, no ensino privado e outras atividades beneficiadas igualmente com o crescimento econômico e das políticas sociais (Tabela 5). 
Tabela 5 - Número de indivíduos que receberam títulos de mestrado no período 1996-2010 e número e proporção destes que também obtiveram título de doutorado no período 1996-2014, por área do conhecimento

\begin{tabular}{|c|c|c|c|c|}
\hline $\begin{array}{c}\text { Classificação } \\
\text { áreas na } \\
\text { Capes }\end{array}$ & $\begin{array}{c}\text { Área do } \\
\text { conhecimento }\end{array}$ & $\begin{array}{c}\text { Titulados } \\
\text { no } \\
\text { mestrado } \\
\text { no período } \\
\mathbf{1 9 9 6 - 2 0 1 0} \\
\text { (A) }\end{array}$ & $\begin{array}{c}\text { Titulados no } \\
\text { mestrado no período } \\
\text { 1996-2010 que } \\
\text { também titularam } \\
\text { no doutorado no } \\
\text { período 1996-2014 } \\
\text { (B) }\end{array}$ & $\begin{array}{c}\text { Proporção } \\
\text { (\%) (B/A) }\end{array}$ \\
\hline 80 & Total & 371.586 & 113.520 & 30,6 \\
\hline 21 & Antropologia & 1.801 & 768 & 42,6 \\
\hline 33 & Sociologia & 5.934 & 2.020 & 34,0 \\
\hline 47 & $\begin{array}{c}\text { Ciência } \\
\text { Política }\end{array}$ & 2.309 & 666 & 28,8 \\
\hline
\end{tabular}

Fonte: CGEE - Mestres e doutores 2015 - Estudos da demografia da base técnicocientífica brasileira (Organização Social supervisionada pelo Ministério da Ciência, Tecnologia, Inovações e Comunicações (MCTIC)- dados Coleta Capes/ Plataforma Sucupira e RAIS).

A titulação de mestrado e doutorado entre 1996-2010 na área foi mais expressiva com um crescimento de $486,9 \%$, praticamente igual à média da pós-graduação brasileira. Nesta, a Antropologia ficou na dianteira, seguida pela Sociologia e Ciência Política. A situação se altera no cômputo dos títulos de doutorado no período, com a Ciência Política e a Antropologia na dianteira (Tabela 6).

Tabela 6 - Número e percentagem de títulos de doutorado concedidos no Brasil no ano de 2014 e taxa de crescimento entre 1996 e 2014, por área do conhecimento

\begin{tabular}{|c|c|c|c|c|}
\hline \multirow{2}{*}{$\begin{array}{c}\text { Classificação } \\
\text { das áreas na } \\
\text { CAPES }\end{array}$} & \multirow{2}{*}{$\begin{array}{c}\text { Área do } \\
\text { conhecimento }\end{array}$} & \multicolumn{3}{|c|}{ Doutores: número de títulos } \\
\hline & & $\begin{array}{l}\text { Número } \\
\text { (2014) }\end{array}$ & \% (2014) & $\begin{array}{l}\text { Crescimento } \\
\text { (\%) 1996-2014 }\end{array}$ \\
\hline 80 & Total & 16.729 & 100,0 & 486,2 \\
\hline 11 & Sociologia & 358 & 2,14 & 486,9 \\
\hline 51 & Antropologia & 101 & 0,60 & 621,4 \\
\hline 53 & Ciência Política & 95 & 0,57 & $1.800,0$ \\
\hline
\end{tabular}

Fonte: CGEE - Mestres e doutores 2015 - Estudos da demografia da base técnicocientíficos brasileira (Organização Social supervisionada pelo Ministério da Ciência, Tecnologia, Inovações e Comunicações (MCTIC)- dados Coleta Capes/ Plataforma Sucupira e RAIS). 
É interessante destacar que nesse período cresceu significativamente a procura de profissionais na área de Antropologia e Ciência Política, o que favoreceu o investimento na formação pós-graduada nessas disciplinas. O mesmo aconteceu com a Sociologia, com um crescimento mais contido, embora nesses títulos estejam incluídos o título de "Ciências Sociais", que pode estar vinculado a qualquer uma das três disciplinas.

Um dado interessante nesse crescimento é a relação graduação-pósgraduação. Como vimos anteriormente, são 109 os cursos de graduação em Ciências Sociais, Sociologia, Sociologia e Política, presenciais e à distância em funcionamento no país. A esse número agregam-se 12 cursos de Antropologia e 19 de Ciência Política (3 à distância), num total aproximado de 140 cursos de graduação da área de Ciências Sociais stricto sensu. Na pósgraduação, esse número aumenta 39\%, chegando a 230 cursos, conforme Tabela 7.

Tabela 7 - Cursos de pós-graduação em Ciências Sociais stricto sensu

\begin{tabular}{|c|c|c|c|c|c|}
\hline & $\begin{array}{c}\text { Total de } \\
\text { cursos }\end{array}$ & Mestrados & Doutorados & $\begin{array}{c}\text { Mestrados } \\
\text { profissionais }\end{array}$ & $\begin{array}{c}\text { Doutorados } \\
\text { profissionais }\end{array}$ \\
\hline $\begin{array}{c}\text { Sociologia } \\
\text { e Ciências } \\
\text { Sociais }\end{array}$ & 89 & 49 & 38 & 02 & \\
\hline $\begin{array}{c}\text { Antropologia e } \\
\text { Arqueologia }\end{array}$ & 59 & 36 & 22 & 01 & 01 \\
\hline $\begin{array}{c}\text { Ciência Política } \\
\text { e Relações } \\
\text { Internacionais }\end{array}$ & 82 & 40 & 24 & 17 & 01 \\
\hline & 230 & 125 & 84 & 20 & \\
\hline
\end{tabular}

Fonte: Capes (Plataforma Sucupira).

Esse quadro evidencia uma característica da pesquisa no Brasil: estar majoritariamente vinculada às universidades públicas, e à pós-graduação como condição para sua realização. A expansão das universidades e a titulação dos docentes pressiona a abertura de novos programas como forma de acomodação dos docentes-pesquisadores contratados. O caráter aberto das profissões das Ciências Sociais possibilita a incorporação de profissionais de outras áreas, e a pós-graduação funciona, em certa medida, como porta de entrada. É comum formados em Direito, Comunicação, Arquitetura, Economia, Administração e outras áreas complementarem sua formação em Sociologia ou Ciências Sociais e atuarem profissionalmente na 
área. Ao contrário de profissões estabelecidas, como Engenharia, Medicina e Direito, que estabelecem barreiras de entrada e controle sobre o mercado, nas Ciências Sociais, assim como nas Ciências Humanas em geral, esse controle é difuso, havendo competição de titulados em várias disciplinas por posições no mercado (BONELLI, 1994).

\section{A pós-graduação e o mercado de trabalho}

Numerosos trabalhos acerca da relação titulação/mercado de trabalho têm sido produzidos pela Capes como forma de ilustrar que a pós-graduação atua positivamente na inserção dos profissionais em empregos mais bem remunerados ${ }^{12}$. A ideia de formação continuada, da busca de formação mais abrangente, tem sido utilizada como elemento explicativo dessa inserção. Entretanto, na área de Sociologia, devemos considerar que o mercado é formado pelo ensino, pesquisa e extensão, majoritariamente em instituições estatais, ONGs e movimentos sociais, universidades e faculdades privadas.

Nas escolas privadas, nota-se que a qualificação funciona mais como garantia de manutenção do conceito e status de universidade e/ ou faculdade a partir das exigências do MEC de um número mínimo de professores titulados. Notícias recorrentes de dispensas em massa de docentes dessas instituições ocorrem com frequência e, com a crescente incorporação dessas escolas por grandes grupos empresariais nacionais e internacionais, a tendência é aumentar a busca de redução de custos e maior lucratividade, com prejuízo do ensino e da pesquisa. Aumenta-se o número de alunos por turmas, reduz-se o número de professores e exigências de titulação. A aprovação recente pelo MEC que as atividades (40\%) na graduação sejam feitas por $\mathrm{EaD}^{13}$, assim como a aprovação pela Capes, também no final do governo, da pós-graduação stricto sensu via $\mathrm{EaD}$, atendendo aos interesses empresariais, tende a precarizar a atividade docente, comprometer sua qualificação e reduzir ainda mais as atividades de pesquisa nessas instituições.

\footnotetext{
${ }^{12}$ Utilizamos aqui os dados sistematizados do CCGE, que, por sua vez, sistematizam dados da Capes da RAIS sobre o mercado de trabalho dos egressos de cursos de pós-graduação.

${ }^{13}$ G1 - 31/12/2018. Graduação presencial poderá ter até 40\% de aulas a distância. Até então, o limite máximo fixado pelo MEC era de $20 \%$ da carga horária. (GLOBO. G1).
} 
Segundo Baltar e Baltar (2017), o perfil do sociólogo tem se confundido com o de professor universitário, embora a demanda por profissionais de Sociologia tenha se mantido regular. Mas essa não tem sido a ênfase da formação que desconsideraria as especificidades da profissão fora da academia. Mesmo assim, a pós-graduação na área faz diferença em termos de emprego.

A pesquisa do CCGE com mestres e doutores titulados a partir de 1996 (Tabela 8), tendo como referência os anos de 2009 e 2014, indica alguns números positivos acerca da situação de mercado dos portadores de títulos de mestres e doutores. No caso dos mestres em Sociologia, houve um crescimento de $47,52 \%$ dos empregados formais, embora com uma variação mínima, positiva, da taxa de formalização desses empregos de 64,3\% para 64,4\%, ao contrário dos titulados em Antropologia e Ciência Política, cujas taxas ficaram negativas. Esse número pode indicar empregos PJ ou de consultorias informais, que não são computados (Tabela 9).

Tabela 8 -Número de mestres (1) titulados no Brasil a partir de 1996, empregados (2) em 2014, por áreas do conhecimento

\begin{tabular}{|c|c|c|c|c|}
\hline \multirow{2}{*}{$\begin{array}{c}\text { Classificação } \\
\text { áreas na } \\
\text { Capes }\end{array}$} & \multirow{2}{*}{$\begin{array}{c}\text { Área do } \\
\text { conhecimento }\end{array}$} & $\begin{array}{c}\text { Número } \\
\mathbf{( 2 0 1 4 )}\end{array}$ & \% (2014) & $\begin{array}{c}\text { Crescimento } \\
\text { (\%) 2014/2009 }\end{array}$ \\
\cline { 3 - 5 } & Total & 16.729 & 100,0 & 486,2 \\
\hline 80 & Sociologia & 4.141 & 1,41 & 47,52 \\
\hline 22 & $\begin{array}{c}\text { Ciência } \\
\text { Política }\end{array}$ & 1.845 & 0,63 & 60.71 \\
\hline 60 & Antropologia & 893 & 0,30 & 52,65 \\
\hline
\end{tabular}

Fonte: CGEE - Mestres e doutores 2015 - Estudos da demografia da base técnicocientífica brasileira (Organização Social supervisionada pelo Ministério da Ciência, Tecnologia, Inovações e Comunicações (MCTIC)- dados Coleta Capes/ Plataforma Sucupira e RAIS), p.123.

Notas:

(1) A população de mestres considerada a cada ano é formada pelo conjunto dos indivíduos que obtiveram títulos de mestrado (acadêmico ou profissional) no Brasil durante o período que vai de 1996 até o referido ano. Foram, no entanto, extraídos dessa população os indivíduos que vieram a também obter título de doutorado até o referido ano. Indivíduos que obtiveram mais de um título de mestrado no período foram considerados apenas uma vez. Nesses casos, a primeira titulação é a que foi tomada em consideração.

(2) A situação de emprego é aferida no dia 31 de dezembro do ano sob análise, de acordo com os registros da RAIS do mesmo ano. 
Tabela 9 -Taxa de emprego (1) formal em 2009 e em 2014 de titulados em programas de mestrado (2) no Brasil a partir de 1996, por área do conhecimento

\begin{tabular}{|c|c|c|c|c|}
\hline \multirow{2}{*}{$\begin{array}{c}\text { Classificação } \\
\text { áreas }\end{array}$} & Área do & \multicolumn{3}{|c|}{ Mestres taxa de emprego formal } \\
\cline { 3 - 5 } & conhecimento & $\mathbf{2 0 0 9}$ & $\mathbf{2 0 1 4}$ & Diferença 2014/2009 \\
\hline 80 & Total & 66,7 & 65,8 & $-0,84$ \\
\hline 37 & Sociologia & 64,3 & 64,4 & 0,1 \\
\hline 40 & Ciência Política & 65,1 & 62,5 & $-2,6$ \\
\hline 78 & Antropologia & 47,0 & 45,8 & $-1,1$ \\
\hline
\end{tabular}

Fonte: CGEE - Mestres e doutores 2015 - Estudos da demografia da base técnicocientífica brasileira (Organização Social supervisionada pelo Ministério da Ciência, Tecnologia, Inovações e Comunicações (MCTIC) - dados Coleta Capes/ Plataforma Sucupira e RAIS).

Notas metodológicas (1) e (2) na Tabela 8.

No caso dos doutores, a taxa de crescimento no período foi maior que a dos mestres pelas exigências dos concursos das universidades públicas do título de doutor para a entrada na carreira. O crescimento da taxa de doutores entre 1996 e 2014 foi de 62,42\%, com uma taxa de emprego formal maior de 77,87\%, em 2009, e 78,57 em 2014, com uma variação positiva de $0,70 \%$ (Tabelas 10 e 11).

Tabela 10 - Número de doutores (1) titulados no Brasil a partir de 1996, empregados (2) em 2014, por áreas do conhecimento

\begin{tabular}{|c|c|c|c|c|}
\hline \multirow{2}{*}{$\begin{array}{c}\text { Classificação } \\
\text { áreas }\end{array}$} & \multirow{2}{*}{$\begin{array}{c}\text { Área do } \\
\text { conhecimento }\end{array}$} & $\begin{array}{c}\text { Número } \\
\mathbf{( 2 0 1 4 )}\end{array}$ & \% (2014) & $\begin{array}{c}\text { Crescimento (\%) } \\
\text { 2014/2009 }\end{array}$ \\
\hline 80 & Total & 16.729 & 100,0 & 486,2 \\
\hline 9 & Sociologia & 3.120 & 2,46 & 62,42 \\
\hline 52 & Ciência Política & 676 & 0,53 & 111,91 \\
\hline 53 & Antropologia & 649 & 0,51 & 74,46 \\
\hline
\end{tabular}

Fonte: CGEE - Mestres e doutores 2015 - Estudos da demografia da base técnicocientífica brasileira (Organização Social supervisionada pelo Ministério da Ciência, Tecnologia, Inovações e Comunicações (MCTIC) - dados Coleta Capes/ Plataforma Sucupira e RAIS).

Notas metodológicas (1) e (2) na Tabela 8. 
Tabela 11 -Taxa de emprego (1) formal em 2009 e em 2014 de titulados em programas de doutorado (2) no Brasil a partir de 1996, por área do conhecimento

\begin{tabular}{|c|c|c|c|c|}
\hline \multirow{2}{*}{$\begin{array}{c}\text { Classificação } \\
\text { áreas }\end{array}$} & Área do & \multicolumn{3}{|c|}{ Doutores: taxa de emprego formal } \\
\cline { 3 - 5 } & conhecimento & $\mathbf{2 0 0 9}$ & $\mathbf{2 0 1 4}$ & Diferença 2014/2009 \\
\hline 80 & Total & 74,77 & 75,47 & 0,71 \\
\hline 17 & Ciência Política & 75,59 & 80,48 & 4,88 \\
\hline 27 & Sociologia & 77,87 & 78,57 & 0,70 \\
\hline 67 & Antropologia & 65,72 & 65,69 & $-0,04$ \\
\hline
\end{tabular}

Fonte: CGEE - Mestres e doutores 2015 - Estudos da demografia da base técnicocientífica brasileira (Organização Social supervisionada pelo Ministério da Ciência, Tecnologia, Inovações e Comunicações (MCTIC) - dados Coleta Capes/ Plataforma Sucupira e RAIS).

Notas metodológicas (1) e (2) na Tabela 8.

Em termos de remuneração, a diferença entre mestres e doutores é substancial, mas indica a forte presença das instituições públicas e suas carreiras, assim como no caso de instituições privadas os salários decorrentes de regimes de trabalho específicos com carreiras, em geral, formalizadas (caso de universidades confessionais e outras fortemente estabelecidas no mercado). No caso do ensino privado, o salário é composto, em grande parte dos casos, pela soma de atividades em diversas escolas ao mesmo tempo (Tabela 12).

Tabela 12 -Remuneração (1) mensal média de mestres (2) titulados no Brasil a partir de 1996, por área do conhecimento, 2009 e 2014 (R\$ de 12/2014)

\begin{tabular}{|c|c|c|c|c|}
\hline \multirow{2}{*}{$\begin{array}{c}\text { Classificação } \\
\text { áreas }\end{array}$} & \multirow{2}{*}{$\begin{array}{c}\text { Área do } \\
\text { conhecimento }\end{array}$} & \multicolumn{3}{|c|}{$\begin{array}{c}\text { Mestres: Remuneração mensal média (R\$ } \\
\text { constantes de 12/4) }\end{array}$} \\
\cline { 3 - 5 } & & $\mathbf{2 0 0 9}$ & $\mathbf{2 0 1 4}$ & Diferença 2009/2014 \\
\hline 80 & Total & 8.880 & 9.719 & 9,4 \\
\hline 07 & Ciência Política & 13.185 & 13.078 & $-0,8$ \\
\hline 50 & Sociologia & 6.913 & 7.710 & 11,5 \\
\hline 68 & Antropologia & 6.518 & 6.833 & 4,8 \\
\hline
\end{tabular}

Fonte: CGEE - Mestres e doutores 2015 - Estudos da demografia da base técnicocientífica brasileira (Organização Social supervisionada pelo Ministério da Ciência, Tecnologia, Inovações e Comunicações (MCTIC) - dados Coleta Capes/ Plataforma Sucupira e RAIS).

Notas metodológicas (1) e (2) na Tabela 8. 
Tanto para mestres como para doutores, a variação salarial foi positiva, $11,5 \%$ para mestres e 16,7\% para doutores, decorrente das negociações salariais das universidades federais no período e da política deliberada de valorização da titulação de doutorado (Tabela 13).

Tabela 13 - Remuneração (1) mensal média de doutores (2) titulados no Brasil a partir de 1996, por área do conhecimento, 2009 e 2014 (R\$ de 12/2014)

\begin{tabular}{|c|c|c|c|c|}
\hline \multirow{2}{*}{$\begin{array}{c}\text { Classificação } \\
\text { áreas }\end{array}$} & \multirow{2}{*}{$\begin{array}{c}\text { Área do } \\
\text { conhecimento }\end{array}$} & \multicolumn{3}{|c|}{$\begin{array}{c}\text { Doutores: Remuneração mensal média (R\$ } \\
\text { constantes de 12/2014) }\end{array}$} \\
\cline { 3 - 5 } & & $\mathbf{2 0 0 9}$ & $\mathbf{2 0 1 4}$ & Diferença 2009/2014 \\
\hline 80 & Total & 11.733 & 13.861 & 18,1 \\
\hline 13 & Ciência Política & 13.616 & 14.998 & 10,2 \\
\hline 40 & Sociologia & 11.565 & 13.499 & 16,7 \\
\hline 65 & Antropologia & 10.309 & 12.471 & 21,0 \\
\hline
\end{tabular}

Fonte: CGEE - Mestres e doutores 2015 - Estudos da demografia da base técnicocientífica brasileira (Organização Social supervisionada pelo Ministério da Ciência, Tecnologia, Inovações e Comunicações (MCTIC) - dados Coleta Capes/ Plataforma Sucupira e RAIS).

Notas metodológicas (1) e (2) na Tabela 8.

\section{A pós-graduação e a mobilidade espacial-institucional}

Feita a caracterização da expansão e institucionalização da área de Sociologia e da importância da pós-graduação para o mercado de trabalho, passaremos a apresentar alguns dados referentes à formação de docentes, sua mobilidade espacial e geracional a partir de sua atuação na pósgraduação. Essa mobilidade é ilustrativa da "nacionalização" da área e consolidação do campo, como afirmamos anteriormente, padronizando em grande medida a formação e a profissionalização, tendo como recorte o mercado de trabalho acadêmico.

Vamos apresentar alguns gráficos especificados regionalmente. Para efeito de comparação, juntamos a região Sudeste (Minas Gerais e Espírito Santo) com a Centro-Oeste. Rio de Janeiro e São Paulo aparecem separadamente por concentrarem, respectivamente, o maior número de programas de pós-graduação no país, o que marcou a configuração do campo da Sociologia historicamente.

No Rio de Janeiro, a formação dos docentes vinculados à pós-graduação concentra-se em programas do próprio Estado. A UFRJ é a mais endógena, 
com 52,7\% dos credenciados formados na própria instituição. Com a crise do IUPERJ em 2009, seus docentes e titulados se distribuíram por outros programas, com presença marcante na PUCRio (8 dos 14 docentes) e na UERJ-Ciências Sociais (PPCIS), em que representam 1/3 dos credenciados. Os titulados no Estado, em seus diversos programas, representam 61,6\% dos docentes-pesquisadores que atuam na pós-graduação. USP e Unicamp são as únicas instituições de fora do Estado a ter um número relevante de titulados, assim como os titulados no exterior, embora em sua maioria anteriores a 2000.

No Estado, a UENF apresenta maior diversidade de formação, assim como o CPDA da UFRRJ, com destaque aos formados no próprio programa com uma característica temática e interdisciplinar. O novo programa do IESP-UERJ Sociologia, por sua vez, destaca-se pelo número de titulados no exterior. Dos 11 titulados (outubro 2018) no exterior, cinco foram depois do ano 2000. Na UENF, dos 21 credenciados, outros representam cinco formados na própria instituição, dois na UFMG, dois na UFJF, um na PUCRio (Gráfico 3).

Gráfico 3 - IES de Titulação/ IES de atuação (PPG)

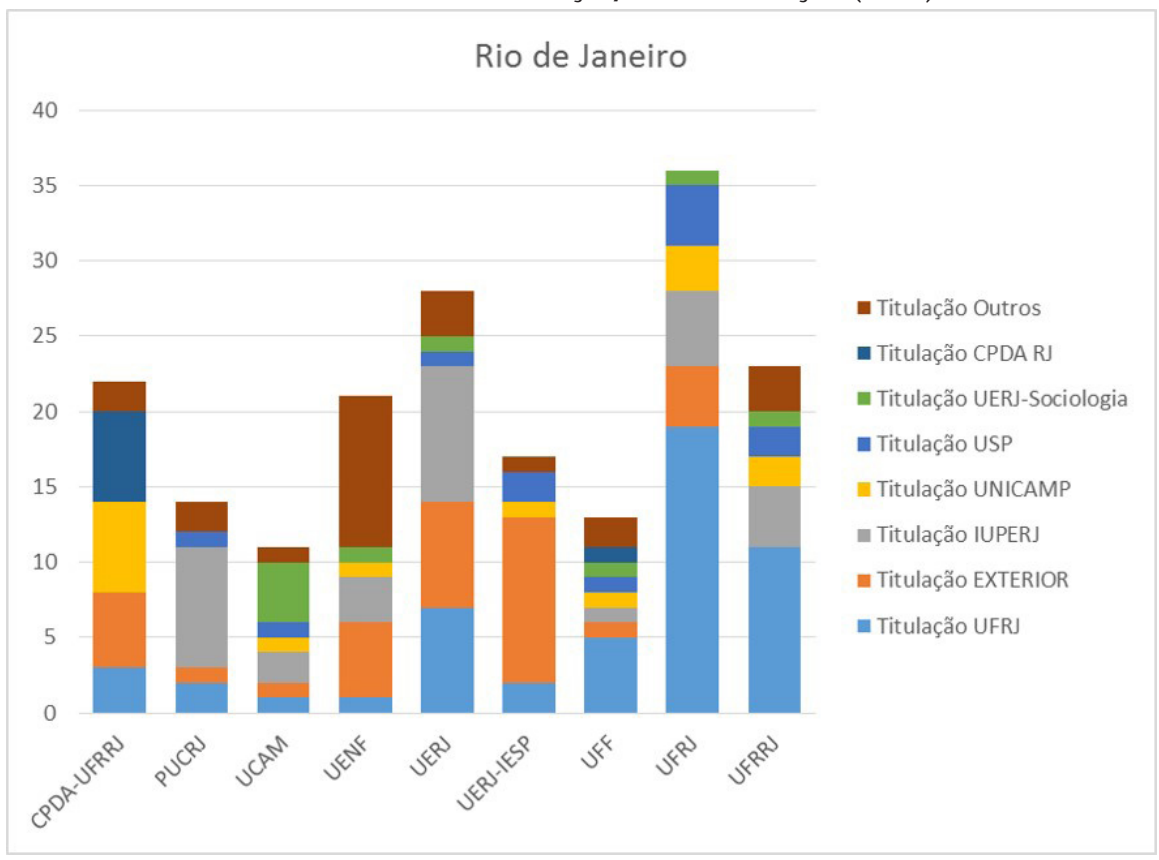

Fonte: Elaborado pelo autor a partir dos sites dos PPGs (2018). 
São Paulo apresenta o maior índice de endogenia do país, com os titulados permanecendo na instituição de formação ou no estado de origem. A USP titulou 41,7\% dos docentes atuantes na pós-graduação, seguida da Unicamp, com os dois programas da área, além de outras titulações com $28,6 \%$, seguida pela PUCSP com $11,6 \%$. As três universidades representando 81,9\% (Gráfico 4).

\section{Gráfico 4 - IES de titulação/ IES de atuação}

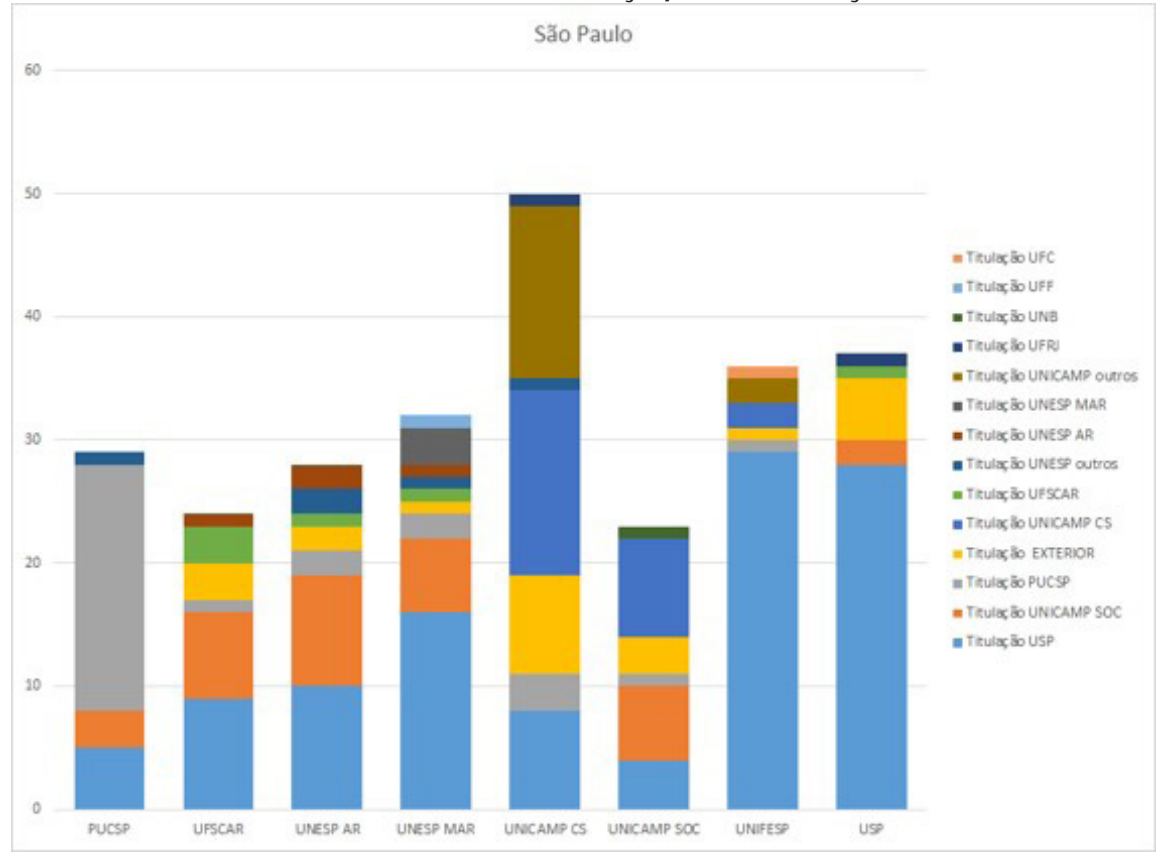

Fonte: Elaborado pelo autor a partir dos sites dos PPGs (2018).

Os programas da USP, PUCSP e Unicamp são os mais endógenos, com a maioria dos seus credenciados sendo formados no próprio programa e/ou instituição. Isto se explica pelo pioneirismo dos programas dessas instituições na área, no caso da USP e PUCSP, assim como da Unicamp, com dois programas, um disciplinar e o outro interdisciplinar ${ }^{14}$. Na UNIFESP,

\footnotetext{
${ }^{14}$ O Programa de Ciências Sociais da Unicamp, com apenas o doutorado, foi organizado para atender inicialmente às três áreas disciplinares que abriram seus mestrados - a Sociologia, a Política e a Antropologia. Posteriormente, foram criados programas disciplinares completos, com mestrado e doutorado, e mantido o de Ciências Sociais, que incorporou docentes das três áreas e mais áreas afins, como Economia, Demografia (presente na proposta original) e Educação.
} 
resultado da expansão das federais com um campus de humanidades na cidade de Guarulhos, região metropolitana de São Paulo, dos seus 36 docentes credenciados no Programa de Ciências Sociais, 29 foram titulados na USP, absorvendo os titulados que se encontravam em outras instituições e/ou atividades. Nos demais, UFSCar e Unesp - Araraquara e Marília -, a titulação pela USP e Unicamp, embora dominante, já divide espaço com formados em seus próprios programas e outros do Estado de São Paulo e exterior.

Nas outras regiões do país nota-se uma maior diversificação da formação, com a predominância crescente de programas consolidados regionalmente.

No Sul, os titulados na UFRGS se destacam numericamente no próprio programa e na UFSM e, em menor escala, nos demais programas do Estado. Em seguida, vem a Unicamp majoritariamente nos estados do Paraná e Santa Catarina, assim como a USP e a PUCSP. Deve-se considerar o caráter mais recente dos doutorados na região em termos comparativos, principalmente com São Paulo. Mesmo assim, a formação no próprio Sul tem sido crescente, destacando-se a UFRGS, a UFPR e a UFSC. É forte ainda a presença dos formados no exterior. Entre as universidades estaduais do Paraná (UEL, UEM e Unioeste) e a UFSC, predomina a formação nas universidades paulistas, como USP, Unicamp e PUCSP (Gráfico 5).

\section{Gráfico 5 - SUL IES de Titulação e IES de institucionalização na pós-graduação}

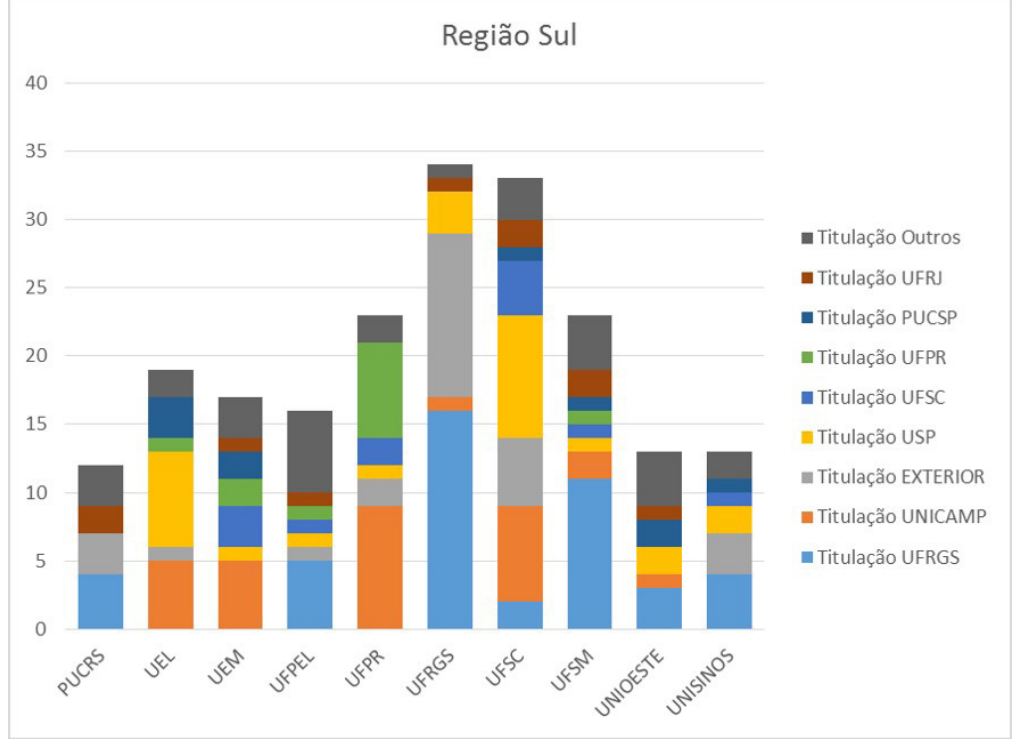

Fonte: Elaborado pelo autor a partir dos sites dos PPGs (2018). 
No Nordeste, a formação é bem diversificada, embora os programas tradicionais tendam a predominar em seus estados. No Ceará, a UFC é responsável pela maioria dos titulados em seu programa e no da UECE. Em Pernambuco, a UFPE titulou a maioria dos docentes da Fundação Joaquim Nabuco, situação similar à da Unifesp, em São Paulo, com a expansão da instituição. O programa da própria UFPE - que ainda tem um número significativo de titulados no exterior, embora seja a geração titulada até 2000 - tem uma presença significativa na maioria dos programas da região. A UFBA, com doutorado mais recente, tem seus titulados no próprio programa, pela USP e no exterior, assim como presença destacada na UFRB.

No total, a maioria dos titulados obtiveram seus títulos fora da região de origem. Cerca de $58 \%$ dos docentes foi titulado no exterior. USP, Unicamp, PUCSP, UFRJ, UFRGS e UnB, UFPe e UFC titularam cerca de $22 \%$ do total (Gráfico 6).

\section{Gráfico 6 - Nordeste IES de Titulação e IES de institucionalização na pós- graduação}

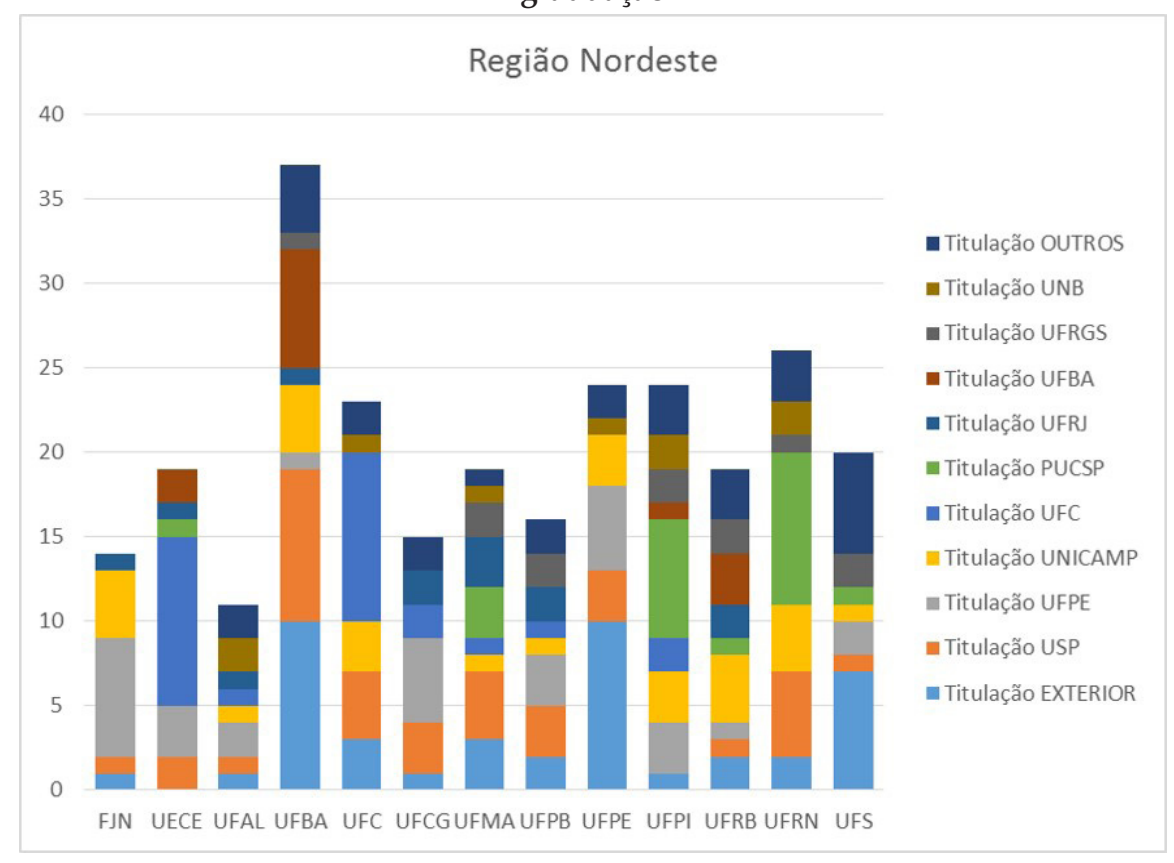

Fonte: Elaborado pelo autor a partir dos sites dos PPGs (2018). 
No Sudeste (excluídos São Paulo e Rio de Janeiro) e Centro-Oeste, a UnB tem credenciados em seu programa $50 \%$ dos docentes titulados na própria instituição e também no programa da UFG. Em Minas, a UFMG tem 60\% titulados em seu próprio programa, mas não possui número significativo de titulados em outros programas do Estado. Unicamp, USP, IUPERJ, Unesp e UFRJ têm uma presença mais significativa. Deve-se considerar a juventude dos programas da região, principalmente em MT e MS, recém-criados, e programas ainda com graus distintos de consolidação, como UFES, UVV, UFU, UFJF e PUC Minas (Gráfico 7).

\section{Gráfico 7 - IES de Titulação e IES de institucionalização na pós-graduação}

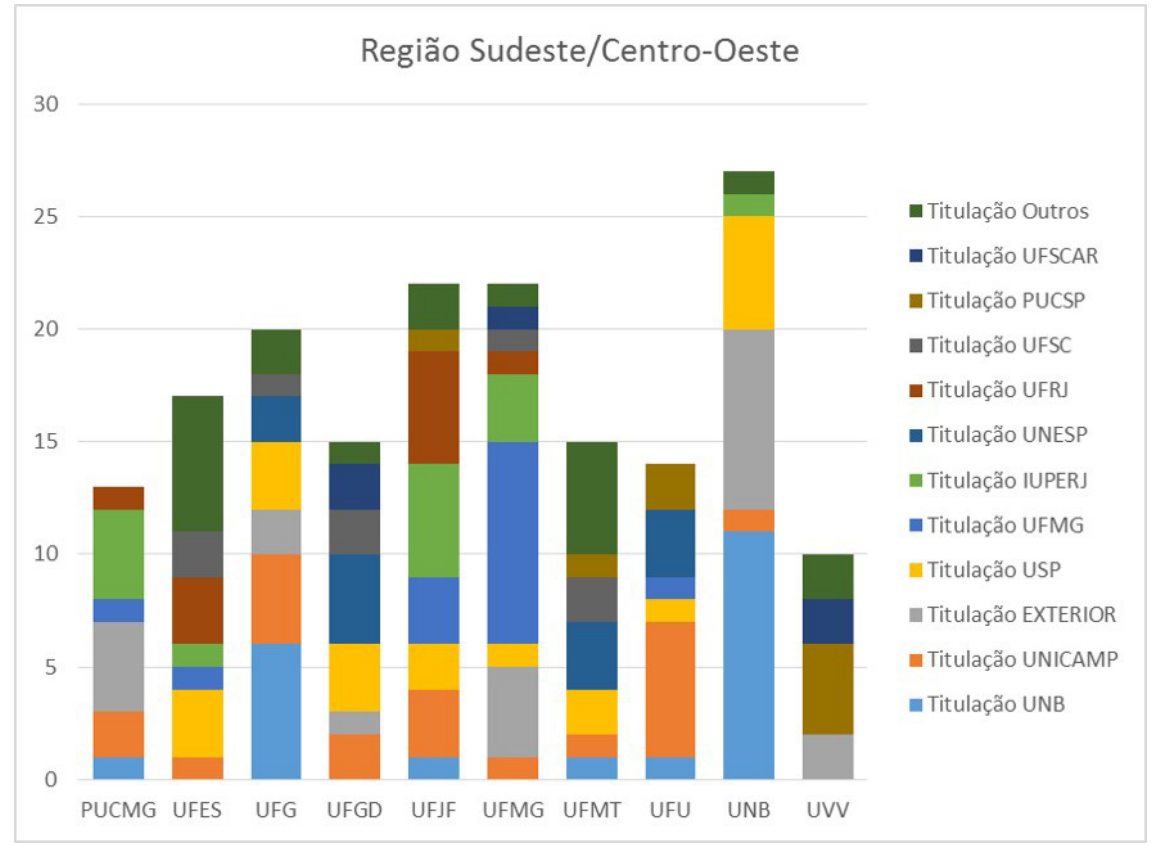

Fonte: Elaborado pelo autor a partir dos sites dos PPGs (2018).

A região Norte tem apenas dois programas disciplinares, o mais antigo na UFPA e o da UFAM. Na UFPA, destacam-se ainda os formados no exterior no período anterior a 2000, em seguida, os formados pela própria instituição, embora a maioria no programa interdisciplinar do NAEA, o Programa de Pós-Graduação em Desenvolvimento sustentável do Trópico Úmido, que chegou a integrar o Comitê de Avaliação da Área de Sociologia até os anos 1990, posteriormente solicitando sua passagem para o comitê interdisciplinar (Gráfico 8). No conjunto, a maioria dos titulados fez seus 
doutorados em outras regiões do país, principalmente na USP, Unicamp, UFRJ.

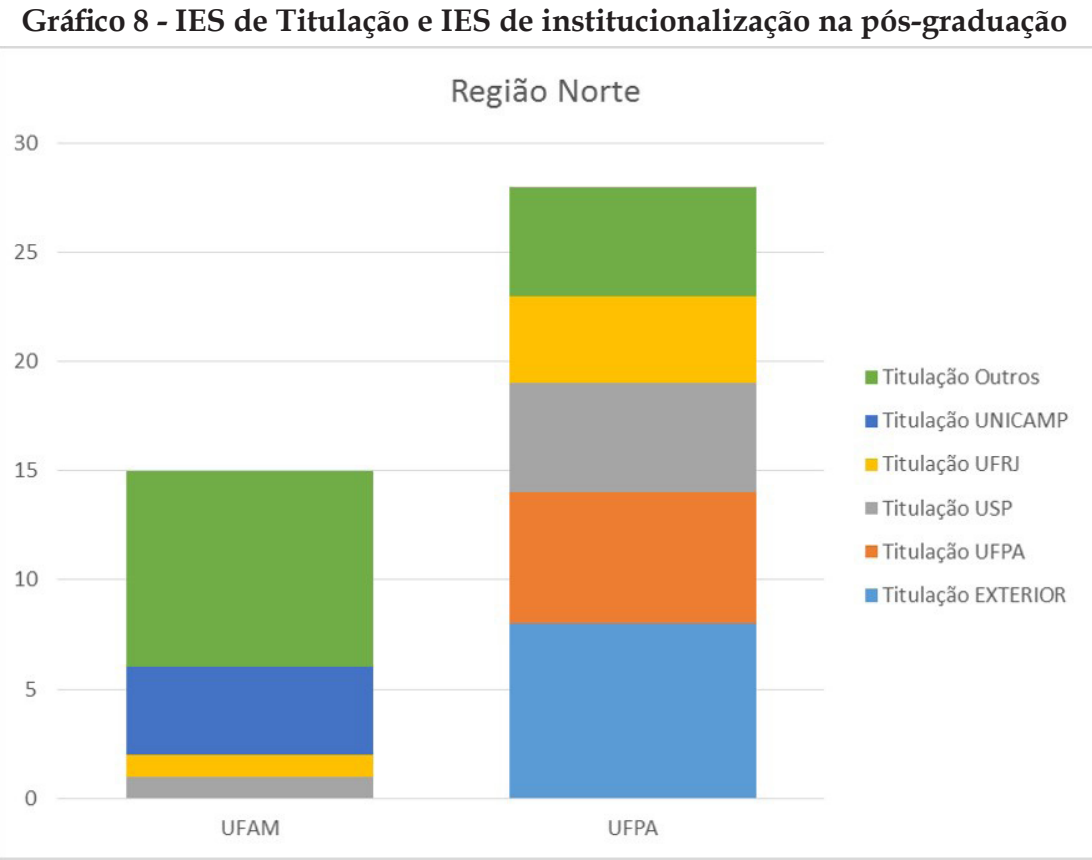

Fonte: Elaborado pelo autor a partir dos sites dos PPGs (2018).

O que fica evidente em todas as regiões é a maior diversidade nas formações fora dos estados de São Paulo e Rio de Janeiro, acompanhando a expansão da formação no país. Entretanto, na pós-graduação, com as exigências de produção e a permanência de professores aposentados como credenciados, ainda é significativa a formação doutoral no exterior e nos programas mais antigos, como USP, Unicamp, PUC e IUPERJ, que abriram essa formação no país, como veremos a seguir.

\section{A mobilidade geracional na pós-graduação}

A formação de doutores da última década tem provocado um grande impacto na pós-graduação, embora haja um relativo equilíbrio geracional, com a presença de professores aposentados que permanecem atuando. Esse equilíbrioé fundamental para a manutenção da qualidade desses programas, evitando os gaps geracionais existentes nos departamentos, os quais, ao 
mesmo tempo que dinamizam e trazem novas perspectivas e linhas de pesquisa, comprometem a continuidade de outras que, em várias situações, caracterizaram a formação e a pesquisa em determinados programas. É importante ressaltar que tempo de titulação não significa tempo de atuação na pós-graduação ou mesmo na universidade, dado que a renovação dos departamentos com o crescimento dos concursos públicos a partir de 2004 se deu a partir de mais de uma década de restrições a novas contratações. Com isso, os gráficos demonstram uma tendência a um equilíbrio que nem sempre reflete o caráter de renovação dos departamentos.

Assim, nas regiões Nordeste, Sul, Sudeste e Centro-Oeste, os gráficos apresentam uma curva gaussiana, demonstrando a dominância de docentes de meio de carreira (Gráficos 9 a 11).

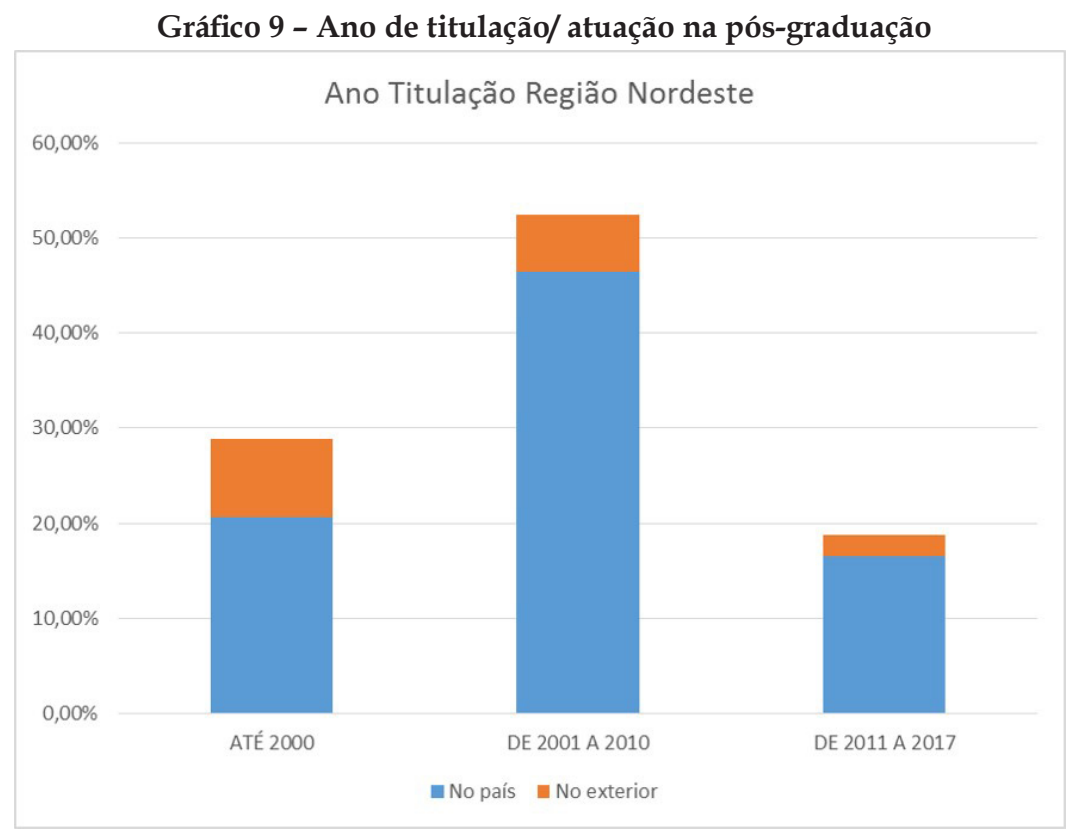

Fonte: Elaborado pelo autor a partir dos sites dos PPGs (2018). 
Gráfico 10 - IES de Titulação e IES de institucionalização na pós-graduação

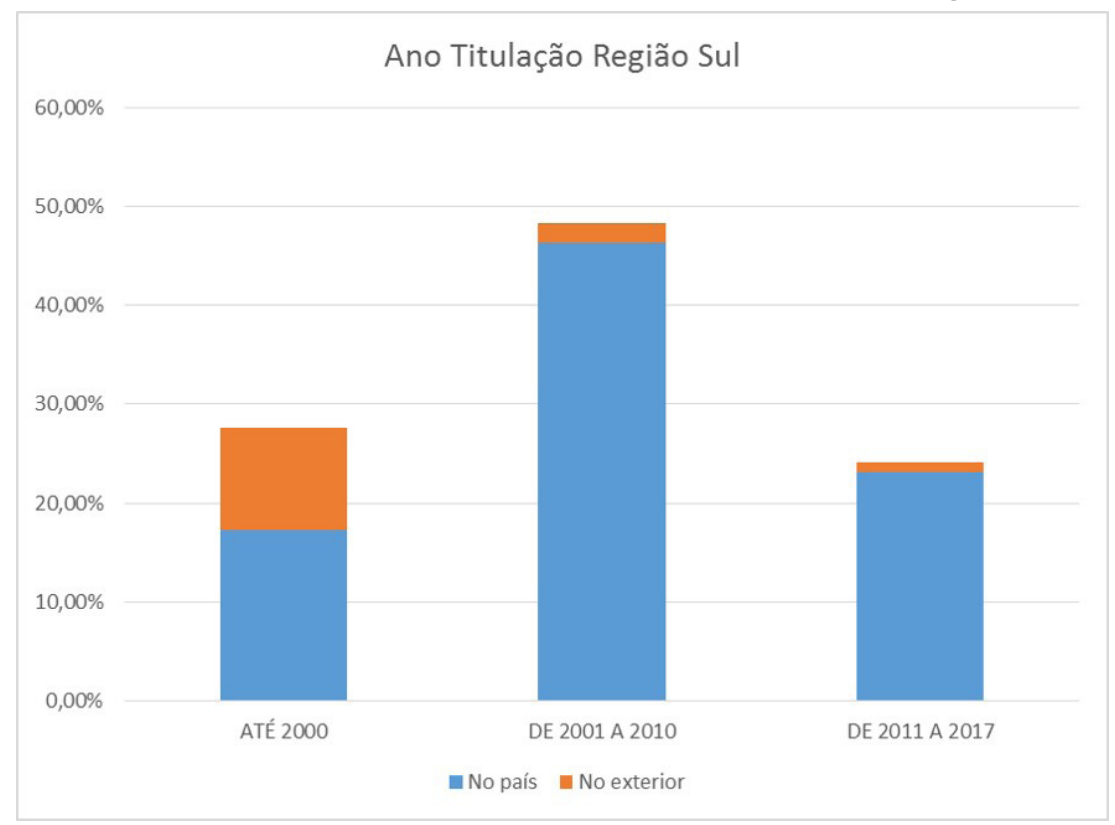

Fonte: Elaborado pelo autor a partir dos sites dos PPGs (2018).

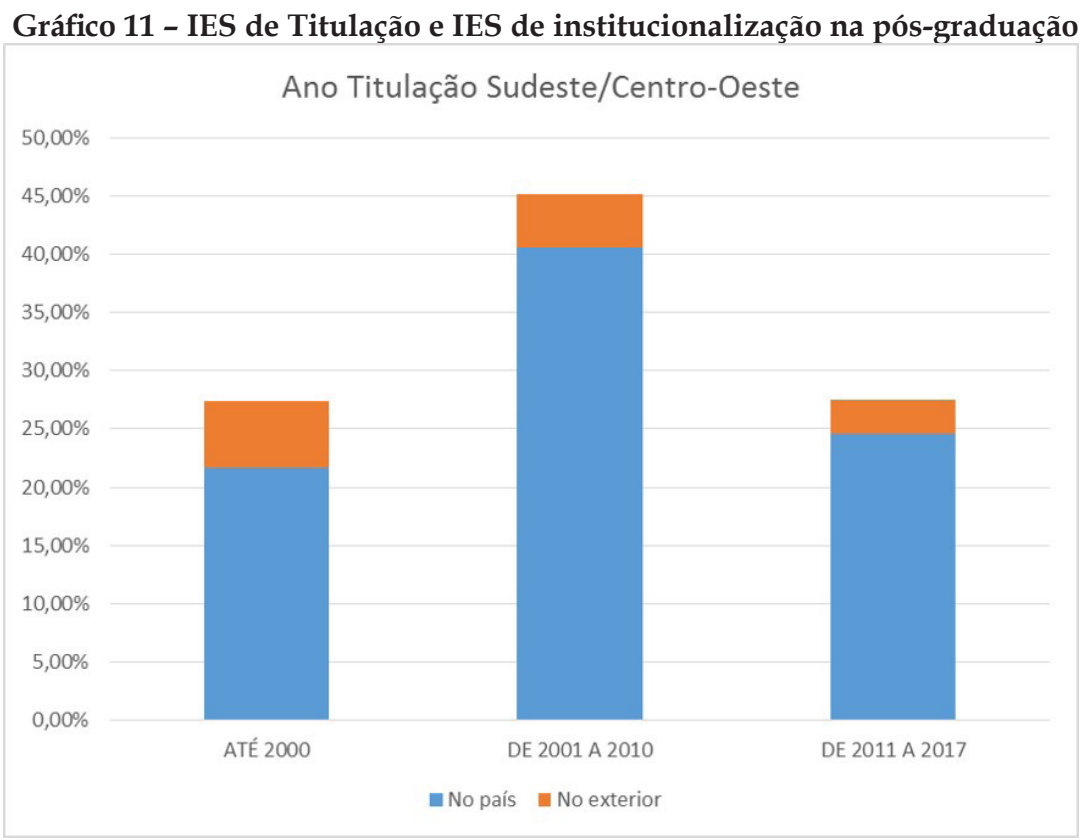

Fonte: Elaborado pelo autor a partir dos sites dos PPGs (2018). 
Essa curva se altera um pouco na região Norte e no Rio de Janeiro, embora por motivos diferentes: no Norte, com apenas dois programas existentes, indica a entrada mais restrita de novos credenciados; no Rio de Janeiro, a competitividade e a existência de uma massa crítica consolidada apontam para uma renovação mais lenta, embora contínua (Gráficos 12 e 13).

Gráfico 12 - IES de Titulação e IES de institucionalização na pós-graduação

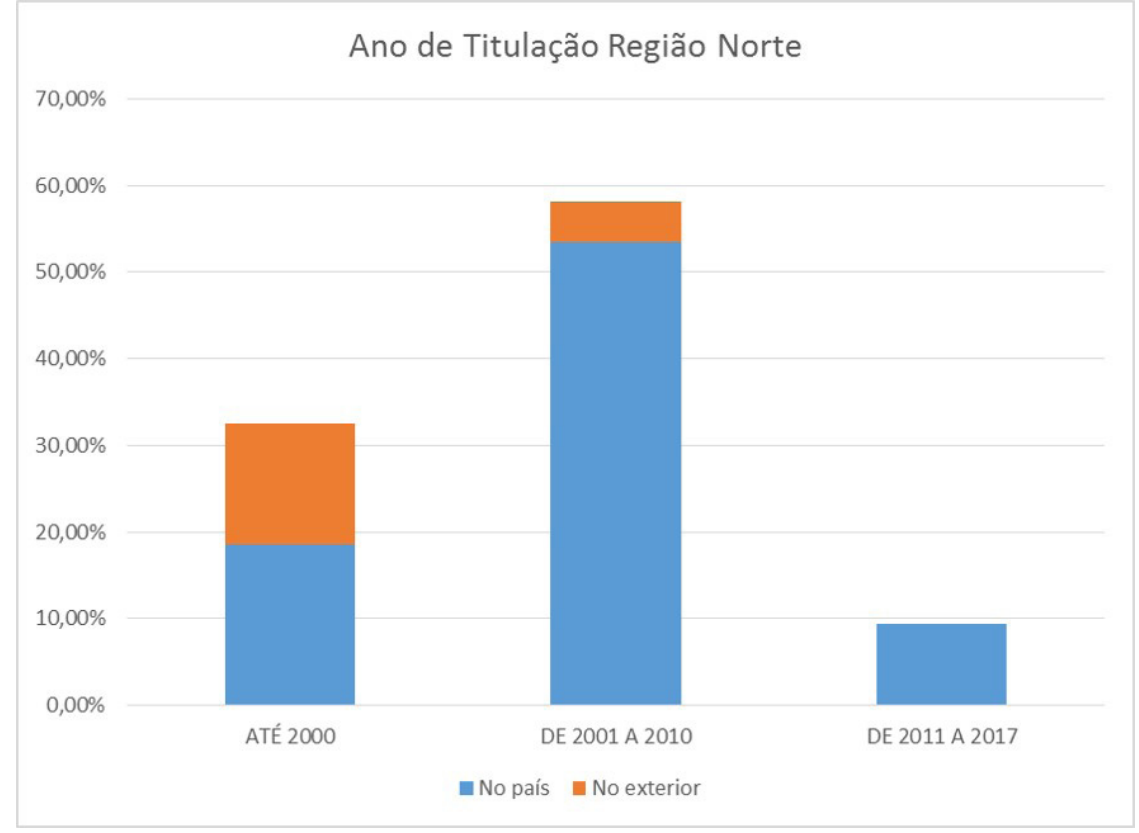

Fonte: Elaborado pelo autor a partir dos sites dos PPGs (2018). 


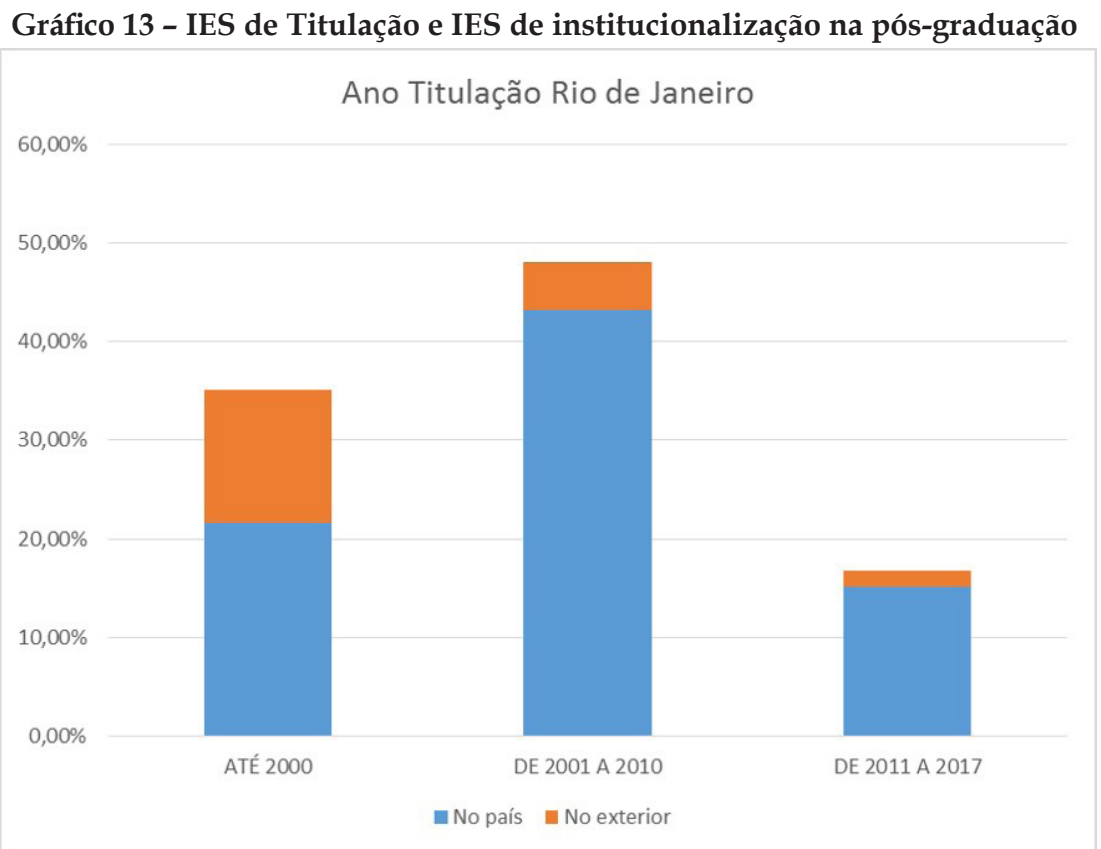

Fonte: Elaborado pelo autor a partir dos sites dos PPGs (2018).

São Paulo aparece fora da curva, por motivos similares ao do Rio de Janeiro, mas aprofundados. Grande parte dos docentes presentes no início da pós-graduação continuam atuando e, mesmo com certa renovação, os titulados até o ano 2000 ainda representam 50\% do total (Gráfico 14). 


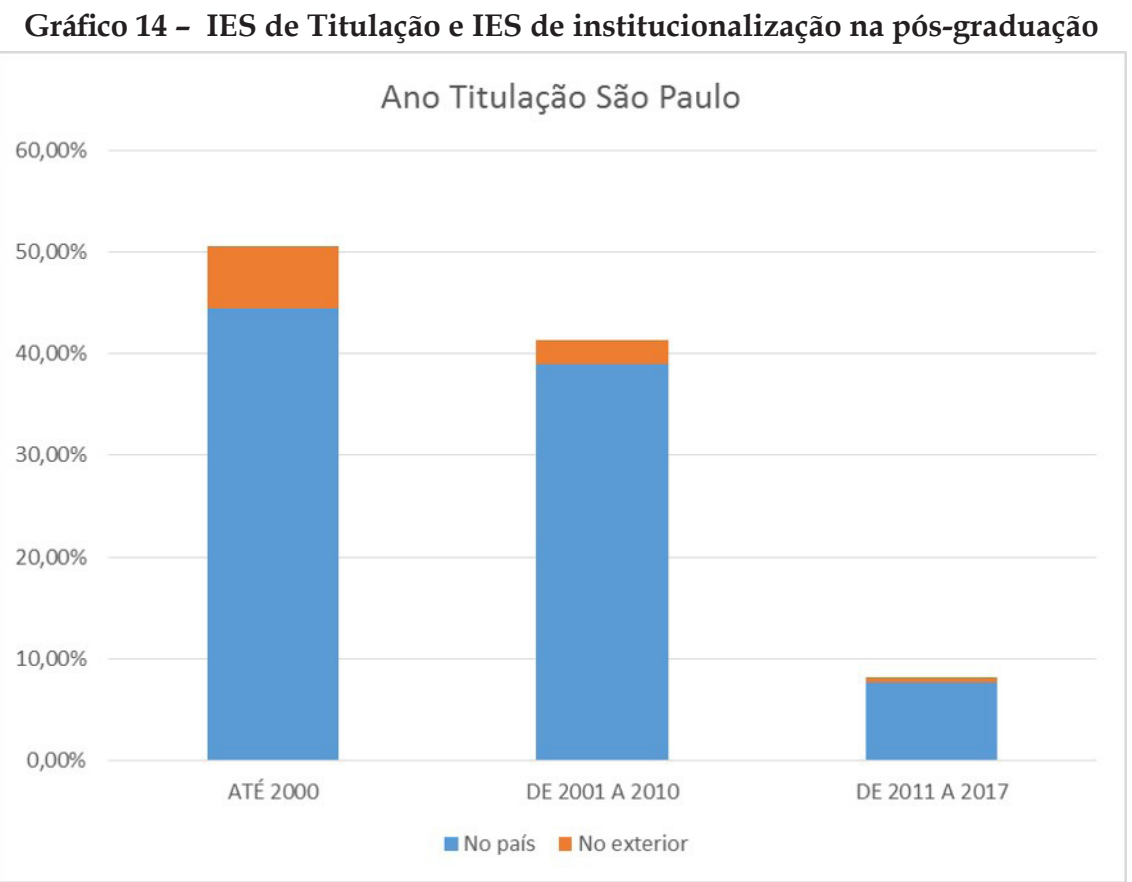

Fonte: Elaborado pelo autor a partir dos sites dos PPGs (2018).

Os dados apresentados sobre a mobilidade geracional na pós-graduação, que apontam para a renovação dos quadros, discreta, mas constante, talvez aparecessem de forma mais distinta e radical se considerássemos os docentes envolvidos nos programas interdisciplinares. Estes se multiplicam principalmente em novos campi sem uma configuração disciplinar consolidada, havendo ora propostas inovadoras em termos de ensino e pesquisa, ora uma forma de juntar pesquisadores com temáticas próximas.

\section{Sociologia, Ciências Sociais e Interdisciplinaridade}

Uma das questões que vêm sendo debatidas na Capes já há algum tempo é a necessidade de revisão de alguns critérios de avaliação para que se continue efetivamente fazendo a discriminação, a partir de indicadores, da excelência dos programas de pós-graduação. Isso aconteceu na década de 1990 com a implementação do Qualis periódico e a mudança de conceitos para notas, além do fato de a maioria dos programas de pós-graduação da área terem atingido padrões de qualidade equivalentes. 
Além desse padrão já atingido, a expansão das últimas décadas deu visibilidade ao que historicamente foi construído no Brasil, como o "campo" das Ciências Sociais, originalmente agrupando três disciplinas com níveis distintos de consolidação e profissionalização: a Sociologia, a Ciência Política e a Antropologia. Isso se tornou o formato dominante nos cursos de graduação em Ciências Sociais, o mesmo acontecendo no início da pósgraduação, embora nesse início já esteja presente uma disciplinarização nas três áreas. A Sociologia, fortemente majoritária, tornou-se sinônimo de Ciências Sociais e também passou a ter, principalmente na pós-graduação, programas disciplinares e, posteriormente com a inclusão da disciplina no ensino médio, cursos de licenciatura e mesmo bacharelado na graduação.

Em entrevista realizada na década de 1990 acerca dos últimos 20 anos das Ciências Sociais no Brasil da época, Elisa Reis destacava a positividade das disputas no campo das Ciências Sociais e sua delimitação disciplinar. Para ela, esse processo resultou do crescimento e da institucionalização da profissão, que foi desvinculando a sobreposição existente entre a Sociologia e a Ciência Política, que muitas vezes se confundiam. Essa situação aconteceu menos entre a Sociologia e a Antropologia, que tiveram percursos institucionais similares, por exemplo, na criação da Sociedade Brasileira de Sociologia (1950) e da Associação Brasileira de Antropologia (1953) ${ }^{15}$.

Na Sociologia, como nas outras disciplinas, segundo afirma Reis, Reis e Velho (1991:246), “a natureza racionalizante da ciência implica numa percepção da postura metódica e disciplinar como recurso analítico. A disciplinaridade funciona como uma convenção, não como uma convicção ou imposição".

As lutas no campo científico movimentam-se entre as regras do jogo construídas em cada campo, o capital simbólico e o reconhecimento que estabelecem essas regras. Um campo é definido a partir dos objetos de disputas que o caracterizam, imperceptível para quem não o integra, e pressupõe que seus integrantes incorporem o habitus que torne compreensíveis leis, regras do jogo e objetos de disputa (BOURDIEU, 1983; 1983a: 89).

No Brasil não foi diferente, e nesse combate a Sociologia foi acusada indiretamente de imperialismo diante das demais. Peirano (2000:19) afirma que a Antropologia foi tratada por muito tempo como uma costela

${ }^{15}$ Sobre a criação das associações, veja-se Lima e Cortês (2013). 
da Sociologia; Forjaz (1997) destaca a influência da Sociologia francesa na Sociologia brasileira e a indistinção entre Sociologia Política e Ciência Política como fatores de inibição do desenvolvimento da Ciência Política - situação que se altera com a instituição do sistema de pós-graduação a partir do final dos anos 1960 e o financiamento por instituições norteamericanas (1997).

Mas os conflitos do campo se distribuem internamente na Sociologia. Nas últimas avaliações da Capes, questiona-se a queda de programas tradicionais na área e que formaram boa parte do campo, dos docentes e pesquisadores na pós-graduação brasileira. Por muito tempo, alguns cursos consolidados funcionaram sem considerar muito os processos avaliatórios que passaram a regular a formação pós-graduada com a expansão do ensino superior. Essa situação começou a ser alterada a partir de 2003, com a maior formalização da avaliação e cobrança aos programas do atendimento aos critérios estabelecidos pela área e o crescimento da pósgraduação, provocando uma maior institucionalização que, por sua vez, levou a críticas à burocratização ou mesmo à neoliberalização da academia, com o privilegiamento do produtivismo presente numa avaliação fundada principalmente em dados quantitativos. Entretanto, ao lado desse movimento de institucionalização, com a polêmica acerca de como e o que avaliar, houve também maior democratização da avaliação, com maior participação dos coordenadores de programas no estabelecimento do documento de área, assim como discussões e seminários da coordenação com a área.

Outra disputa presente no comitê de Sociologia está entre os programas disciplinares e os interdisciplinares de Ciências Sociais e que tipo de formação seria mais adequada. Isto ocorre em parte pela diversidade assumida pelos programas de Ciências Sociais na pós-graduação, que funcionam ora de forma temática, integrando as três disciplinas em torno de uma proposta, ora como cursos que formam nas três disciplinas, sendo que, no geral, o orientador dirige as pesquisas para uma delas. Como foi dito, com a expansão das universidades e da pós-graduação, as áreas de Ciência Política e Antropologia expandiram fortemente seus programas disciplinares. A partir da existência de um número de docentes considerados adequados pelos documentos das áreas, cursos disciplinares foram criados. Nos cursos ou programas de Ciências Sociais, ora existe uma predominância da Sociologia, ora não existem condições institucionais para abertura de cursos disciplinares. Numa terceira vertente, mantêm-se propostas integrativas de interdisciplinaridade. 
Além disso, houve um crescimento no período de 1996-2014 de 736,4\% nos doutorados interdisciplinares (92 em 2014) e 715,6\% nos mestrados (261, em 2014). Na Câmara II da Coordenação Sociais e Humanidades da Capes, estes de certa forma ampliaram as propostas de interdisciplinaridade das Ciências Sociais, incluindo disciplinas como Economia, História, Direito, Geografia. Na Câmara II, alguns dos programas poderiam ser considerados de Ciências Sociais ampliados, ficando em questão a especificidade e a manutenção da proposta das Ciências Sociais stricto sensu, modelo ainda vigente.

Seguem alguns exemplos de programas que estão na Câmara de Sociais e Humanidades da Área Interdisciplinar da Capes. Percebe-se que a maioria dos programas interdisciplinares está em universidades novas ou campi novos de universidades já existentes. Na ausência de um corpo docente com formação disciplinar, a interdisciplinaridade surge mais como opção de ter um programa, ou curso, do que efetivamente uma proposta diferenciada em grande parte dos casos. Isto considerando a vinculação pesquisa-pós-graduação que exige que os doutores estejam em cursos de pós como forma de acesso a determinados recursos.

Mesmo em cursos mais antigos e ou consolidados, nota-se que os titulados dos cursos interdisciplinares, ao solicitarem financiamento de pesquisa e ou bolsas de capacitação, terminam por destacar a formação disciplinar como forma de acesso, por não existir a opção Interdisciplinar, ou talvez pela dificuldade de se criar uma. O mesmo ocorre no mercado de trabalho acadêmico. Quando os concursos são na mesma universidade de titulação, esta é incorporada entre as titulações aceitas. Em outras situações isso não ocorre. Alguns exemplos dos cursos interdisciplinares podem ser assim agrupados: Cultura e Sociedade; Ciências Sociais e Humanas; Interdisciplinar em Humanidades; Sociedade e Território; Políticas Públicas; Memória e Patrimônio; Estudos latino-americanos (Quadro 4).

Quadro 4 - Programas que integram a Câmara de Sociais e Humanidades da Coordenação da Área Interdisciplinar - Selecionados pela proximidade dos Programas de Ciências Sociais stricto sensu

\begin{tabular}{|c|c|c|c|}
\hline Nome do curso & Nível & Instituição & Estado \\
\hline Sociologia e Direito & $\begin{array}{l}\text { Mestrado/ } \\
\text { Doutorado }\end{array}$ & UFF & RJ \\
\hline Cultura e Territorialidades & Mestrado & UFF & RJ \\
\hline Estudos de Cultura e Território & Mestrado & UFT & TO \\
\hline Dinâmicas Territoriais e Cultura & Mestrado & UNEAL & AL \\
\hline
\end{tabular}




\begin{tabular}{|c|c|c|c|}
\hline Nome do curso & Nível & Instituição & Estado \\
\hline Sociedade, Cultura e Fronteiras & $\begin{array}{l}\text { Mestrado/ } \\
\text { Doutorado }\end{array}$ & UNIOESTE & PR \\
\hline Relações Étnico-Raciais & Mestrado & CEFET & RJ \\
\hline $\begin{array}{l}\text { Relações Étnicas e } \\
\text { Contemporaneidade }\end{array}$ & Mestrado & UESB & BA \\
\hline Estudos Étnicos e Africanos & $\begin{array}{l}\text { Mestrado/ } \\
\text { Doutorado }\end{array}$ & UFBA & BA \\
\hline $\begin{array}{c}\text { Família na Sociedade } \\
\text { Contemporânea }\end{array}$ & $\begin{array}{l}\text { Mestrado/ } \\
\text { Doutorado }\end{array}$ & UCSAL & BA \\
\hline $\begin{array}{l}\text { Estudos Interdisciplinares sobre } \\
\text { Mulheres, Gênero e Feminismo }\end{array}$ & $\begin{array}{l}\text { Mestrado/ } \\
\text { Doutorado }\end{array}$ & UFBA & BA \\
\hline $\begin{array}{c}\text { Interdisciplinar em Ciências } \\
\text { Humanas }\end{array}$ & Mestrado & UFFS & $\mathrm{BA}$ \\
\hline Ciências Humanas & $\begin{array}{c}\text { Mestrado } \\
\text { Profissional }\end{array}$ & UFVJM & $\begin{array}{l}\text { BA/ } \\
\text { MG }\end{array}$ \\
\hline $\begin{array}{c}\text { Interdisciplinar em Ciências } \\
\text { Humanas }\end{array}$ & Doutorado & UFSC & SC \\
\hline $\begin{array}{l}\text { Interdisciplinar em Ciências } \\
\text { Humanas e Sociais Aplicadas }\end{array}$ & Mestrado & $\begin{array}{l}\text { UNICAMP- } \\
\text { Limeira }\end{array}$ & $\mathrm{SP}$ \\
\hline Interdisciplinar em Humanidades & Mestrado & UNILAB & $\mathrm{CE}$ \\
\hline Ciências Humanas & Mestrado & UEA & $\mathrm{AM}$ \\
\hline Ciências Sociais e Humanas & Mestrado & UERN & $\mathrm{RN}$ \\
\hline Ciências Humanas e Sociais & $\begin{array}{l}\text { Mestrado/ } \\
\text { Doutorado }\end{array}$ & UFABC & $\mathrm{SP}$ \\
\hline Humanidades, Culturas e Artes & $\begin{array}{l}\text { Mestrado/ } \\
\text { Doutorado }\end{array}$ & UNIGRANRIO & RJ \\
\hline Ciências da Sociedade & Mestrado & UFOPA & PA \\
\hline $\begin{array}{c}\text { Processos e manifestações } \\
\text { culturais }\end{array}$ & $\begin{array}{l}\text { Mestrado/ } \\
\text { Doutorado }\end{array}$ & FEEVALE & RS \\
\hline $\begin{array}{c}\text { Diversidade Cultural e Inclusão } \\
\text { Social }\end{array}$ & $\begin{array}{l}\text { Mestrado/ } \\
\text { Doutorado }\end{array}$ & FEEVALE & RS \\
\hline Sociedade e Cultura na Amazônia & $\begin{array}{l}\text { Mestrado/ } \\
\text { Doutorado }\end{array}$ & UFAM & $\mathrm{AM}$ \\
\hline $\begin{array}{c}\text { Dinâmicas Territoriais e Sociedade } \\
\text { na Amazônia }\end{array}$ & Mestrado & UNIFESSPA & PA \\
\hline Cultura e Sociedade & Mestrado & UFMA & MA \\
\hline $\begin{array}{l}\text { Estudos de Cultura } \\
\text { Contemporânea }\end{array}$ & $\begin{array}{l}\text { Mestrado/ } \\
\text { Doutorado }\end{array}$ & UFMT & MT \\
\hline
\end{tabular}




\begin{tabular}{|c|c|c|c|}
\hline Nome do curso & Nível & Instituição & Estado \\
\hline Sociedade e Desenvolvimento & Mestrado & UNESPAR & PR \\
\hline Desenvolvimento e Sociedade & Mestrado & UNIARP & SC \\
\hline $\begin{array}{c}\text { Práticas Socioculturais e } \\
\text { Desenvolvimento Social }\end{array}$ & Mestrado & UNICRUZ & RS \\
\hline
\end{tabular}

Fonte: Capes - Plataforma Sucupira (janeiro 2019).

Sem dúvida, as fronteiras das Ciências Sociais nem sempre são identificáveis, o que também ocorre nas ciências de forma geral. Entretanto, como afirmam Reis, Reis e Velho (1997:245), ao se referirem à teoria social clássica, na medida em que formulações transcendem os limites de uma disciplina, elas estimulam o desenvolvimento de novas especializações que provocam o avanço do conhecimento. Isso não é uma recusa à interdisciplinaridade inerente à própria formação da Sociologia e à importância dessa interdisciplinaridade na formação, mas de se evitarem as generalizações excessivas ou o discurso filosofante que às vezes perpassam as justificativas da formação do sociólogo, como se a profissionalização fosse apenas uma questão secundária para os estudantes e profissionais.

\section{Concluindo}

Os dados aqui apresentados fornecem um painel da institucionalização da Sociologia, tendo a formação pós-graduada como eixo. Busquei demonstrar a construção do campo e sua "nacionalização", não no sentido restritivo do nacional, mas de sua expansão territorial de construção de uma comunidade acadêmica e profissional na área.

Para isto destaquei a expansão da formação graduada e pós-graduada e as questões que se colocam a partir dessa expansão. Uma delas é a existência de um número maior de cursos de pós-graduação comparativamente à graduação, considerando a área de Ciências Sociais stricto sensu, mas destacando a constituição da formação disciplinar da Sociologia, e as lutas presentes no campo das Ciências Sociais. Uma forma de responder a essa questão é atribuir o caráter complementar da formação em Sociologia e Ciências Sociais para algumas profissões como Direito, Educação, História, Economia, Jornalismo, Filosofia, Medicina e outras, nas quais os titulados tendem a permanecer. Uma outra encontra-se na descoberta da vocação, fazendo com que migrem a partir da formação pós-graduada. Como a titulação pós-graduada se sobrepõe à graduada nas humanidades, isso é 
relativamente comum. No Ensino Médio, levantamento realizado em 2012 indicava que apenas $19,42 \%$ dos professores com formação em Sociologia ou Ciências Sociais ministravam a disciplina, o que refletia o caráter recente da obrigatoriedade da Sociologia, por um lado, e por outro a pouca atração exercida pelo magistério entre os formados na área ${ }^{16}$.

A formação em Sociologia e Ciências Sociais se distribui por todo o país com padrões de qualidade significativo, o que é ilustrativo da maior presença da Sociologia brasileira em fóruns mundiais. Isso se deu a partir de uma capacitação docente propiciada dentro e fora do país, que se institucionalizou e consolidou. A prevalência da avaliação da pósgraduação pela Capes, na qual a pesquisa e as publicações tiveram um papel determinante, se constituiu instrumento importante para a "nacionalização" dessa formação e atuação.

Através dos programas de pós tentei apresentar o processo de mobilidade docente entre as regiões do país. Os dados nesse sentido restringem-se apenas à pós-graduação dada a dificuldade de levantamento de dados sobre docentes dos departamentos de Sociologia ou de Ciências Sociais nem sempre on-line, assim como dos docentes dos Institutos Federais que também tiverem forte expansão. Isto permitiria um panorama mais completo da mobilidade espacial e geracional. Com as novas universidades e campi, houve uma incorporação de profissionais graduados em todo o país, o que é ilustrado com os dados acerca de sua incorporação pelo mercado de trabalho nas universidades públicas e privadas e mesmo fora do âmbito acadêmico. Outra questão relevante é o impacto dessa mobilidade nas cidades e regiões para onde os pesquisadores se deslocam, assim como os processos de consolidação que não duram menos que 10 anos, mas isso é assunto para uma próxima pesquisa.

Por fim, vale retomar a questão da crise econômica e das mudanças políticas dos últimos dois anos, que tem significado uma profunda regressão em termos de investimentos e de perspectivas do desenvolvimento científico e tecnológico. Além disso, temos as ameaças concretas à

\footnotetext{
${ }^{16}$ Bodart e Silva (2016) afirmam que o censo apresenta diversos problemas de preenchimento e que esses números devem ser relativizados. Em pesquisa que realizaram em todo o país, o número é bem maior: 76, 7\%, mas foi realizado em um blog destinado a professores da área, o que também limita seu alcance. Mesmo assim, com a retirada da obrigatoriedade das Ciências Sociais com a reforma do Ensino Médio em 2017, deve acrescentar novos dados acerca da busca pelo magistério entre formados na área.
} 
universidade e sua autonomia pela radicalização de um discurso moralistareligioso que vai na contramão das conquistas das últimas décadas. Num artigo publicado em 1958, Florestan Fernandes destacava uma percepção negativa da Sociologia no período por setores conservadores da sociedade, vista então como "uma ameaça aos fundamentos emocionais e morais da ordem estabelecida", sendo que tudo que fosse entendido como sociológico deveria ser "repelido como fonte de perigos reais ou potenciais para os costumes ou a mentalidade do povo brasileiro" (1977[1958], p.57-58). Após 60 anos, assistimos à repetição desse discurso. A Sociologia, mais uma vez, é penalizada pelo obscurantismo que se espraia pela sociedade, reforçando a ignorância acerca da disciplina e de suas possibilidades.

\section{Referências}

ALMEIDA, M.H.T.

(1987). Castelos na Areia: Dilemas da Institucionalização das Ciências Sociais no Rio de Janeiro (1930-1964). BIB, Rio de Janeiro, n. 24. p. $41-60,2^{\circ}$ semestre.

BALTAR, R; BALTAR, C.S.

(2017). A Sociologia como profissão. Revista Brasileira de Sociologia, v. 05, n. 10, p.259289, maio/ago.

BARREIRA, I.F; CORTES, S.V.; LIMA, J.C.

(2018). A Sociologia fora do eixo: diversidades regionais e campo da pós-graduação no Brasil. Revista Brasileira de Sociologia, v. 06, n. 13, p.76-103, maio/ago.

BODART, C.N; SILVA, R.S.

(2016). 0 perfil do professor brasileiro de Sociologia do ensino médio e sua percepção da condição docente. Inter-Legere - Revista de Pós-Graduação em Ciências Sociais da UFRN, Natal no 18, p. 168-189.

BONELLI, M. G.

(1994). 0 mercado de trabalho dos cientistas sociais. Revista Brasileira de Ciências Sociais, São Paulo, v. 09, n.25, p. 110-126.

BOURDIEU, P.

(1983). 0 campo científico. In: ORTIZ, R. (Org.). Sociologia. São Paulo: Ática, 1983. p. 122155.
BOURDIEU, P.

(1983a) Algumas propriedades dos Campos. In: BOURDIEU, P. Questões de sociologia. Rio de Janeiro, Editora Marco Zero, p. 89-94.

CCGE.

(2016). Mestres e doutores 2015 - Estudos da demografia da base técnico-científica brasileira. Brasília, DF, Centro de Gestão e Estudos Estratégicos. Disponivel em: <https://www.cgee.org.br/ documents/10182/734063/Mestres_ Doutores_2015_Vs3.pdf> Acesso em: 15 mar. 2018.

DS. Departamento de Sociologia USP. Disponível em: <http://sociologia.fflch.usp.br/pos/ apresentacao $>$

e-MEC. Ministério da Educação. Disponível em:< emec.mec.gov.br>

FARIAS, E.; TAVOLARO, S.B.F.

(2017). A prática da Sociologia na UnB: da abertura de horizontes intelectuais aos anseios de renovação. In: BOMENY, $H$. (org.). Ensino de Sociologia na graduação: perspectivas e desafios. São Paulo: SBSAnnablume, p.77-109.

FERNANDES, F.

(1977[1958]). 0 padrão de trabalho científico dos sociólogos brasileiros. In FERNANDES, F. $A$ Sociologia no Brasil. Petrópolis, Vozes. 
FORJAZ, M.C.S.

(1997). A emergência da Ciência Política no Brasil: aspectos institucionais. Revista Brasileira de Ciências Sociais, v. 12 n. 35, p. 101-120.

GLOB0. G1. Educação. Disponível em: <https://g1.globo.com/educacao/ noticia/2018/12/31/graduacao-presencialpodera-ter-ate-40-de-aulas-a-distancia. ghtml>

ICS. Instituto de Ciências Sociais. Disponível em: <http://www.ics.uerj.br/site/index.php/ institucional/apresenta\%C3\%A7\%C3\%A30. html>

LIMA, J.C.; CORTÊS, S.V.

(2013). A Sociologia no Brasil e a interdisciplinaridade nas ciências sociais. Civitas, Porto Alegre, v. 13, n. 3, p. 416-435, set.-dez.

MEC-SESU.

(1965). Parecer no 977/65. Definição dos cursos de pós-graduação. Relator Newton Sucupira. Disponivel em: <https://www.capes.gov. $\mathrm{br} /$ images/stories/download/legislacao/ Parecer_CESU_977_1965.pdf> Acesso em: 17 ago. 2018.

PEIRAN0, Mariza G. S.

(2000). A Antropologia como ciência social no Brasil. Etnográfica, v. 4, n. 2, p. 219-232.

PERLATTO, F.

(2017). Sociologia e Ciências sociais na graduação: especialização \& imaginação interdisciplinar. In: BOMENY, H. Ensino de Sociologia na graduação: perspectivas e desafios. São Paulo, SBS-Annablume, p.145170.
REIS, E.P.

(1991). Reflexões transversas sobre transdisciplinaridade e ensino de Ciências Sociais. In: BOMENY, H; BIRMAN, P. As assim chamadas Ciências Sociais. Rio de Janeiro, UERJ-Relume Dumará, p. 243-249.

REIS, E.P; REIS, F.W.; VELHO, G.

(1997). As Ciências Sociais nos últimos 20 anos: três perspectivas. Revista Brasileira de Ciências Sociais, v. 12 n. 35, p.7-28.

LEIS, H.R.

(2000). A tristeza de ser sociólogo no século XXI. Dados, v.43 n.4, p. 737-760.

SAVIANI, D.

(2008). Cadernos Cedes, Campinas, v. 28, n. 76, p. 291-312, set. /dez.

SUCUPIRA, N.

(1980). Antecedentes e primórdios da pósgraduação. Forum educ., Rio de Janeiro, 4 (4), p. 3-18, out./dez.

UERJ. A Universidade. Apresentação. Disponível em: $\quad<$ http://www.uerj.br/a-uerj/auniversidade $>$

UERJ. A Universidade. Histórico. Disponível em: <http://www.uerj.br/a-uerj/a-universidade>

\section{Recebido em}

março de 2019

\section{Aprovado em}

março de 2019 